\title{
Alzheimer's disease: a clinical practice-oriented review
}

\author{
Serviço de Neurologia, Hospital de Egas Moniz, Centro Hospitalar de Lisboa Ocidental, Lisboa, Portugal \\ 2 Faculdade de Ciências Médicas, Universidade nova de Lisboa, Lisboa, Portugal \\ ${ }^{3}$ Centro de Estudos de Doenças Crónicas, Lisboa, Portugal \\ ${ }^{4}$ Hospital Beatriz Ângelo, Loures, Portugal
}

Luísa Alves ${ }^{1,2,3}{ }^{*}$, Ana Sofia A. Correia ${ }^{1}$, Rita Miguel ${ }^{1}$, Paulo Alegria ${ }^{4}$ and Paulo Bugalho ${ }^{1,2,3}$

\section{Edited by:}

João Massano, Centro Hospitalar de

São João and Faculty of Medicine

University of Porto, Portugal

Reviewed by:

Paula I. Moreira, University of

Coimbra, Portugal

Stefano F. Cappa, Vita-Salute San

Raffaele University, Italy

Gainotti Guido, Policlinico Gemelli,

Italy

\section{*Correspondence:}

Luísa Alves, Serviço de Neurologia,

Hospital de Egas Moniz, Centro

Hospitalar de Lisboa Ocidental, Rua

da Junqueira 126, 1349-019 Lisboa,

Portugal.

e-mail: asiulselva@gmail.com
Investigation in the field of Alzheimer's disease (AD), the commonest cause of dementia, has been very active in recent years and it may be difficult for the clinician to keep up with all the innovations and to be aware of the implications they have in clinical practice. The authors, thus, reviewed recent literature on the theme in order to provide the clinician with an updated overview, intended to support decision-making on aspects of diagnosis and management. This article begins to focus on the concept of $A D$ and on its pathogenesis. Afterward, epidemiology and non-genetic risk factors are approached. Genetics, including genetic risk factors and guidelines for genetic testing, are mentioned next. Recommendations for diagnosis of $A D$, including recently proposed criteria, are then reviewed. Data on the variants of $A D$ is presented. First approach to the patient is dealt with next, followed by neuropsychological evaluation. Biomarkers, namely magnetic resonance imaging, single photon emission tomography, FDG PET, PiB PET, CSF tau, and A $\beta$ analysis, as well as available data on their diagnostic accuracy, are also discussed. Factors predicting rate of disease progression are briefly mentioned. Finally, non-pharmacological and pharmacological treatments, including established and emerging drugs, are addressed.

Keywords: Alzheimer, AD pathogenesis, AD genetics, AD diagnosis, AD variants, AD neuropsychological evaluation, $A D$ biomarkers, $A D$ treatment

\section{CONCEPT OF ALZHEIMER'S DISEASE}

The present conceptualization of Alzheimer's disease (AD) is based on autopsy findings of widespread neuritic plaques and neurofibrillary tangles (NFT), described for the first time in 1906 by Alois Alzheimer in a case with early symptom onset (Alzheimer et al., 1995). The concept was subsequently generalized to late-onset cases when Blessed et al. observed identical pathology in elderly patients (Blessed et al., 1968; Seshadri et al., 2011).

The term "AD" may have distinct meanings in different contexts. $\mathrm{AD}$ has, in some settings, referred to the neuropathological criteria for $\mathrm{AD}$, and, in other, to the clinical syndrome of progressive cognitive decline, typically at the stage of AD dementia (Sperling et al., 2011). The National Institute on Aging-Alzheimer's Association (NIA-AA) workgroup on diagnostic guidelines for AD decided to define $\mathrm{AD}$ as encompassing the underlying pathophysiological disease process (Sperling et al., 2011) as opposed to having $\mathrm{AD}$ connote only the clinical stages of disease as proposed by the International Working Group for New Research Criteria for the Diagnosis of AD (Dubois et al., 2010). The NIA-AA workgroup thus considers that $\mathrm{AD}$ can be used to refer to dementia stages, as well as to MCI and pre-MCI phases.

Evidence from genetic at-risk and aging cohorts suggests that there may be a time lag of at least a decade between the beginning of the pathological cascade of $\mathrm{AD}$ and the onset of clinical impairment. The NIA-AA workgroup postulates that individuals with biomarker evidence of early $\mathrm{AD}$ pathology (AD-P) are at increased risk of progression to $\mathrm{AD}$ dementia (AD-D). However, the ability of the biomarkers of AD-P to predict the ulterior clinical course of cognitively normal persons remains to be established, and it is acknowledged that some of these individuals will never exhibit clinical symptoms in their lifetime (Sperling et al., 2011).

\section{PATHOGENESIS}

$\mathrm{AD}$ is the most frequent cerebral proteopathy (Jucker and Walker, 2011). Macroscopically, the $\mathrm{AD}$ brain is characterized by atrophy of the hippocampal formation and of the cerebral cortex, primarily involving the fronto-temporal association cortex, combined with ventricular enlargement, especially of the temporal horn, all of these findings being greater than expected for age (Walsh and Selkoe, 2004; Perl, 2010). Microscopically, its neuropathological hallmarks are the combined presence of extracellular $\beta$-amyloid-containing plaques and intraneuronal NFTs, the latter being formed by abnormally hyperphosphorylated tau protein (Terry, 1963; Alzheimer et al., 1995). The $\beta$-amyloid (A $\beta$ ) peptide and tau protein are thought to play a critical role in $\mathrm{AD}$ development, but several other mechanisms of neurodegeneration have been proposed, including pro-inflammatory responses (Wyss-Coray, 2007), mitochondrial dysfunction (Reddy, 2011), oxidative stress (Cai et al., 2011), genetic and environmental factors (Nelson et al., 2011), and apoptosis (Cai et al., 2011). The deleterious effects of these pathological changes provide the substrate for the etiopathogenesis of $\mathrm{AD}$, and converge, ultimately, to synaptic dysfunction and neuronal cell loss (Götz et al., 2004; Walsh and Selkoe, 2004; LaFerla and Oddo, 2005; Arendt, 2009; Takahashi et al., 2010). This process occurs in particularly vulnerable brain 
areas, such as those responsible for memory and cognition, namely the limbic and association cortices and some subcortical nuclei with large cortical projections (Walsh and Selkoe, 2004; LaFerla, 2010; Perl, 2010).

The pathological interaction between $A \beta_{42}$ and tau proteins and their relative contribution to neurodegeneration, synaptic and neuronal loss have been extensively investigated, but still remain to be completely elucidated.

The $\beta$-amyloid protein, a physiological peptide with a characteristic $\beta$-pleated sheet configuration, derives from sequential cleavage of the amyloid precursor protein (APP) by $\beta$ secretase, followed by $\gamma$ secretase (Glenner and Wong, 1984). A $\beta$ can vary in length at the c-terminus, according to the pattern of cleavage of APP. The $A \beta_{1-40}$ isoform (with a total of 40 amino acid residues) is the most prevalent, followed by the $A \beta_{1-42}$ isoform (with 42 amino acid residues). The latter has hydrophobic properties and aggregates more readily than the $A \beta_{1-40}$ isoform, which turns it more amyloidogenic and prone to polymerize (Perl, 2010). A $\beta$ that escapes from proteolytic degradation aggregates and polymerizes in various structurally distinct forms, including oligomeric, protofibrillar, amylospheroid, and fibrillar forms.

In the $\mathrm{AD}$ brain, neuritic plaques are composed of a central core containing $\beta$-amyloid protein, surrounded by clusters of dystrophic axons and dendrites (or neurites) and by glial recruitment (LaFerla and Oddo, 2005; Perl, 2010). A $\beta$ deposits also tend to accumulate in the walls of the leptomeningeal, cerebral cortical and cerebellar blood vessels. Cerebral amyloid angiopathy is correlated with $\mathrm{AD}$ pathogenesis and may lead to vascular rupture and multiple lobar hemorrhages (Nicoll et al., 2004). The A $\beta$ deposition on parenchyma or vascular walls in the brain appears to result from an increased anabolic activity or a decreased catabolic activity of $A \beta$.

Several mutations involving the APP gene, or genes encoding secretase complex components, can promote the amyloidogenic pathway and increase the $A \beta_{42} / A \beta_{40}$ ratio, promoting its aggregation. The study of the early onset familiar forms of $\mathrm{AD}$, histopathologically indistinguishable from the sporadic form, provides compelling evidence for the $\mathrm{A} \beta$ protein role in the initiation of the neurotoxic cascade, corroborated by experiments involving animal and tissue-culture models (Götz et al., 2004). However, for the $\mathrm{AD}$ sporadic form, which is the more prevalent, totaling more than $95 \%$ of cases, the pathogenic trigger remains unidentified (Götz et al., 2004).

The "amyloid cascade hypothesis" postulates that the excessive formation and deposition of insoluble fibrillar $A \beta$, with consequent aggregation in plaques, is the initiating event in $\mathrm{AD}$ pathogenesis. This first insult triggers, secondarily, a neurotoxic cascade, including NFT formation, which ultimately leads to synaptic and neuronal loss in critical areas related with cognitive functions like memory (Herrup, 2010). However, neuropathological investigations have found a weak correlation between cerebral amyloid plaque burden and the severity of dementia (Terry et al., 1991; Nagy et al., 1996; Ingelsson, 2004). Moreover, evidence from earlier studies has suggested that the formation of soluble non-fibrillar $\mathrm{A} \beta_{42}$ assemblies, termed oligomers and composed of small aggregates of 2-12 A $\beta$ peptides, rather than insoluble amyloid plaques, may play a pivotal role in the $\mathrm{AD}$ neurodegenerative cascade. Some in vitro studies suggest that, in the early stages of $\mathrm{AD}, \mathrm{A} \beta$ oligomers, through a potent pro-inflammatory response induction, attenuate microglial phagocytic function and, consequently, impair the clearance of fibrillar $A \beta$, promoting its deposition in the brain (Pan, 2011). In animal models, $A \beta$ oligomers can be found in the hipoccampal CA1 region and in the entorhinal cortex, prior to the development of amyloid plaques and NFT (Wirths et al., 2001). There is also robust evidence, from studies involving transgenic mice and/or human $\mathrm{AD}$ patients, demonstrating that the early accumulation of intraneuronal $A \beta$ oligomers can induce downstream effects, such as mitochondrial dysfunction (LaFerla et al., 2007; Amadoro et al., 2012), microgliosis and astrocytosis (Walsh and Selkoe, 2004), free radicals formation, oxidative stress and hyperphosphorylation of tau protein (Walsh and Selkoe, 2004; LaFerla and Oddo, 2005), synaptic dysfunction and neurotransmitter deficits (Walsh and Selkoe, 2004; Bao et al., 2012), leading to synaptic dysruption and cognitive decline (Walsh and Selkoe, 2004; LaFerla and Oddo, 2005; Arendt, 2009).

Besides amyloid plaques, the other major histopathological hallmark of $\mathrm{AD}$ consists of intraneuronal neurofibrillary lesions, which appear as NFT in soma or apical dendrites, as neuropil threads in distal dendrites and associated with $\mathrm{A} \beta$ plaques in dystrophic neurites. These proteinaceous aggregates consist of paired helical filaments, formed by hyperphosphorylated tau protein. Tau is a microtubule-associated protein, responsible for the assembly and stability of microtubules in the neuronal cell and for axoplasmatic transport. The microtubule connection is regulated by a complex interplay of isoform tau expression and tau phosphorylation (Perl, 2010). In the AD brain, tau protein becomes abnormally hyperphosphorylated at several Ser/Thr residues, detaches from axonal microtubules and aggregates into insoluble NFT. These changes result in disruption of axonal transport and intracellular organelles, including mitochondria (Reddy, 2011). Several phosphokinases have been implicated in tau hyperphosphorylation, namely glycogen synthase kinase $3 \beta$ (GSK3 $\beta$ ), cyclin dependent kinase 5 (CDK5) and extracellular signal-related kinase 2 (ERK2; Ballard et al., 2011a). Tau protein is the main constituent of NFT, but other proteins have been identified, such as ubiquitin (Perry et al., 1987), cholinesterases (Mesulam and Moran, 1987) and A4 amyloid protein (Hyman et al., 1989). There is evidence, based on an animal and tissue-culture study, that neurofibrillar degeneration may trigger or facilitate multiple pathological changes, including intraneuronal $A \beta$ deposition, oxidative damage and glial activation, all of which can participate in mitochondrial dysfunction and neuronal damage (Götz et al., 2004).

Contrarily to what was observed for amyloid plaques, severity of dementia has been strongly correlated with NFT density (in studies involving human AD patients; Nagy et al., 1996), as well as with soluble oligomeric A $\beta$ (Arendt, 2009).

Tau deposition and neurodegeneration occur in stereotyped fashion, progressing over six stages: stages I-II represent the clinically silent involvement of transentorhinal cortex; stages III-IV are characterized by lesions in entorhinal/transentorhinal regions and correspond to the phase of mild cognitive decline; in stages $\mathrm{V}-\mathrm{VI}$, there is severe neocortical destruction and fully developed dementia (Braak and Braak, 1995; Perl, 2010). Recent investigation 
involving human brains indicates that pre-tangle material, able to induce NFT pathology, develops early in noradrenergic projection neurons of the locus coeruleus, before involvement of the transentorhinal region (Braak and Del Tredici, 2011). Tau pathology may then progress in a prodromical phase, during five or more decades, until it reaches a clinical threshold (Hyman and Goméz-Isla, 1994; Braak and Del Tredici, 2011; Nelson et al., 2011). These findings indicate that $\mathrm{AD}$ is not a mere extension of normal aging and challenge the traditional view suggesting that $A \beta$ deposition precedes and triggers tau pathology (Gómez-Ramos and Asunción Morán, 2007; Braak and Del Tredici, 2011).

Synaptic loss in the hippocampus and neocortex is widely considered the major correlate of cognitive decline (Terry et al., 1991; Coleman and Yao, 2003; Walsh and Selkoe, 2004). Defects in synaptic transmission occur early in the disease, before the deposition of amyloid plaques or NFTs, and progress slowly (Walsh and Selkoe, 2004; Arendt, 2009). Several studies using AD human samples have found reduced expression of a group of genes encoding proteins involved in synaptic vesicle traffic, with consequent depletion of neurotransmitter systems and synaptic/neuronal loss (Coleman and Yao, 2003; Yao et al., 2003). Synaptic failure may lead to disruption of neuronal circuits and subsequently result in cognitive decline, even before structural cellular lesions (Yao et al., 2003; Arendt, 2009).

Studies on AD human samples indicate a strong anatomical correlation between synaptic loss markers and tangle formation (Honer et al., 1992; Callahan et al., 1999, 2002; Coleman and Yao, 2003). Furthermore, investigation using animal models has demonstrated the combined occurrence of $\mathrm{A} \beta_{42}$ and hyperphosphorylated tau in hippocampal CA1 region, within neurites and postsynaptically, during the early stages of $\mathrm{AD}$ pathogenesis (Takahashi et al., 2010).

Despite major advances in our understanding of the $\mathrm{AD}$ neuropathology, it is still a matter of great debate and much remains to be explained.

\section{GENETICS}

\section{GENETIC RISK FACTORS}

AD can be divided into early $(<60-65$ years) and late $(>60-$ 65 years) onset forms. According to family history, AD cases may be classified as autosomal dominant, familial or sporadic (Goldman et al., 2011; Table 1).
Late-onset $\mathrm{AD}$ has a substantial genetic component, with an estimated heritability of 58-79\% (Gatz et al., 2006; Wingo et al., 2012). It is probably governed by an array of low penetrance common risk alleles across a number of different loci (Avramopoulos, 2009). In the early 1990s, the association between the APOE gene and late-onset AD was described (Corder et al., 1993; Saunders et al., 1993; Strittmatter et al., 1993a,b). The APOE gene has been repeatedly implicated in the pathogenesis of $\mathrm{AD}$ and a GenomeWide Association Study (GWAS) confirmed that this is the major susceptibility gene for late-onset forms (Coon et al., 2007). There are three common alleles of $A P O E(\varepsilon 2, \varepsilon 3, \varepsilon 4)$, corresponding to six phenotypes. $\mathrm{AD}$ is associated with the $\varepsilon 4$ allele, the presence of which increases the risk and reduces the average age at onset of $\mathrm{AD}$ in a dose-dependent manner (carriers of two APOE $\varepsilon 4$ alleles have a higher risk and an earlier onset of $\mathrm{AD}$ than heterozygous subjects). Estimates of the increased risk conferred by the $A P O E \varepsilon 4$ vary widely. In a recent study, the lifetime risk of $\mathrm{AD}$ at the age of 85 ranged from 51 to $52 \%$ for $A P O E \varepsilon 4 / \varepsilon 4$ male carriers to $60-68 \%$ for $A P O E \varepsilon 4 / \varepsilon 4$ female carriers and from 22 to $23 \%$ for $A P O E \varepsilon 4 / \varepsilon 3$ male carriers to $30-35 \%$ for $A P O E \varepsilon 4 / \varepsilon 3$ female carriers. The odds ratio for $\mathrm{AD}$ of onset between the ages of 60 and 69 was of 35.1 in $A P O E \varepsilon 4$ homozygotes and of 4.2 in $\varepsilon 4 / \varepsilon 3$ heterozygotes (Genin et al., 2011). APOE $\varepsilon 4$ allele is neither necessary nor sufficient for developing AD (Corder et al., 1993; Farrer et al., 1997).

The early onset forms comprise about $6-7 \%$ of all cases of AD (Campion et al., 1999; Nussbaum and Ellis, 2003). Autosomal dominant disease is usually found in early onset $\mathrm{AD}$ families (Bertram and Tanzi, 2005). However, almost $40 \%$ of the patients with early onset $\mathrm{AD}$ are sporadic cases (with a negative family history; van Duijn et al., 1994; Campion et al., 1999). Three genes have been implicated in early onset AD: APP, presenilin 1 (PSEN1), and presenilin 2 (PSEN2). The discovery of the first autosomal dominant mutations in APP (Goate et al., 1991) was followed by the identification of autosomal dominant mutations in the PSEN1 (Schellenberg et al., 1992; Sherrington et al., 1995) and PSEN2 genes (Levy-Lahad et al., 1995a,b; Rogaev et al., 1995). The mutations in any of these three genes result in a shift in the metabolism of APP such that more of a 42 aminoacid form of $A \beta$ is produced (Hardy, 1997). These mutations cause AD with nearly complete penetrance. Nevertheless, they may present with heterogeneous phenotypes (Sherrington et al., 1996; Tedde et al., 2003), and recently an APP mutation that causes disease only in

Table 1 | Alzheimer Disease Genetics Division according to the American College of Medical Genetics and the National Society of Genetic Counselors.

\begin{tabular}{|c|c|c|}
\hline & Feature & Definition \\
\hline \multirow[t]{2}{*}{ Age of onset } & Early onset $(\sim 6-7 \%)^{*}$ & $<60-65$ years \\
\hline & Late-onset ( 93-94\%)* & $>60-65$ years \\
\hline \multirow[t]{3}{*}{ Family history } & Autosomal dominant $(<5 \%)$ & $\begin{array}{l}\text { Disease that occurs in at least three individuals in two or more generations, with two of the individuals } \\
\text { being first-degree relatives of the third }\end{array}$ \\
\hline & Familial ( 15-25\%) & $\begin{array}{l}\text { Disease that occurs in more than one individual and at least two of the affected individuals are } \\
\text { third-degree relatives or closer }\end{array}$ \\
\hline & Sporadic ( 75\%) & Isolated case in the family or cases separated by more than three degrees of relationship \\
\hline
\end{tabular}

${ }^{*}$ Campion et al. (1999), Nussbaum and Ellis (2003). 
the homozygous state was described (Di Fede et al., 2009). In contrast to mutations in PSEN1, mutations in PSEN2 are a relatively rare cause of familial AD (Sherrington et al., 1996; Campion et al., 1999). The age of symptom onset in patients with PSEN1 mutations is generally 25-65 years and it is similar among affected members of the same family. In contrast, individuals with PSEN2 are typically older at presentation (45-88 years) and the age of onset is variable among relatives of the same family (Sherrington et al., 1996). Mutations in APP, PSEN1, and PSEN2 are found in up to $82 \%$ of patients with autosomal dominant AD. It is likely that additional genes influence the pathophysiology of early onset AD (Janssen et al., 2003; Goldman et al., 2011). APOE gene is a risk factor for early onset AD (van Duijn et al., 1994) with odds ratio of 5.6 in $\varepsilon 4$ homozygous individuals and of 2.1 in heterozygous $\varepsilon 4 / \varepsilon 3$ cases (Genin et al., 2011). A recent study estimates that the early onset AD heritability is of $92-100 \%$, which is compatible with an almost entirely genetically based disease. However, the concordance among siblings is of $21.6 \%$ and between parents and offspring of $10 \%$ or less. The authors (Wingo et al., 2012) consider that the most likely explanation for these results is that approximately $90 \%$ of early onset $\mathrm{AD}$ cases are due to autosomal recessive causes.

Since 2009, four GWAS and a three-stage analysis of the GWAS resulted in the identification of nine novel loci associated with late-onset AD: CLU, PICALM, CR1, BIN1, ABCA7, MS4A cluster (MS4A6A/MS4A4E), CD2AP, CD33, and EPHA1 (Harold et al., 2009; Lambert et al., 2009; Seshadri et al., 2010; Hollingworth et al., 2011a,b; Naj et al., 2011). Other studies replicated some of these associations (Carrasquillo et al., 2010, 2011a,b; Corneveaux et al., 2010; Jun et al., 2010; Antúnez et al., 2011a,b; Lambert et al., 2011; Kamboh et al., 2012). Examining the amount of genetic risk effect attributable to these genes (other than $A P O E$ ), the most strongly associated single-nucleotide polymorphisms at each locus have population attributable fractions between 2.72 and $5.97 \%$, with a cumulative population attributable fraction for non-APOE loci estimated to be as much as 35\% (Naj et al., 2011).

It has been suggested (Lambert et al., 2009; Lambert and Amouyel, 2011) that, in familial early onset $\mathrm{AD}$, the $\mathrm{A} \beta$ peptides accumulate through overproduction and that, in late-onset forms, the $A \beta$ excessive deposition is related to an insidious impairment of clearance of $A \beta$ peptides (Mawuenyega et al., 2010).

Morgan (2011) described three new pathways implicated in late-onset $\mathrm{AD}$ :

(1) Immune system function (implicated genes: $C L U, C R 1$, $A B C A 7, M S 4 A$ cluster, CD33 and EPHA1). Specific immune responses may be capable of inducing $A \beta$ degradation, avoiding accumulation of these peptides (Lambert and Amouyel, 2011). It was also suggested that $\mathrm{AD}$ risk variants may cause changes to the complement system, which can re-ignite programmed synaptic loss (Hollingworth et al., 2011b).

(2) Cholesterol metabolism (implicated genes: $A P O E, C L U$, and $A B C A 7)$. As cholesterol promotes synapse formation, interference with cholesterol processing through $\mathrm{AD}$ risk gene activity can be a mechanism of synaptic disintegration (Hollingworth et al., 2011b).
(3) Synaptic dysfunction and cell membrane processes (implicated genes: PICALM, BIN1, CD33, CD2AP, and EPHA1), including endocytosis (Hollingworth et al., 2011a). Although these processes diverge from the amyloid hypothesis, it was suggested that toxic $\mathrm{A} \beta$ may have a modulatory effect on them (Morgan, 2011).

SORL1 is involved in the processing and trafficking of APP into recycling pathways, as demonstrated in a study involving in vitro experiments, mice models and human AD samples (Andersen et al., 2005). A recent meta-analysis of genetic data from casecontrol studies suggests that mutations in SORL1 may play a role in the pathogenesis of late-onset AD (Reitz et al., 2011), but their effect on the risk of disease seems to be modest (Rogaeva et al., 2007).

Recently, a variable-length poly-T (deoxythymidine homopolymer) polymorphism in the TOMM40 gene, which is located next to the $A P O E$ gene in a region of strong linkage disequilibrium, was described and found to be associated with the age of onset of late-onset AD (Lutz et al., 2010; Roses, 2010; Roses et al., 2010). This association is still uncertain and it is unknown whether the poly-T repeat affects risk of $\mathrm{AD}$ through an APOE-dependent or a totally independent mechanism (Cruchaga et al., 2011).

\section{GENETIC TESTING}

The American College of Medical Genetics and the National Society of Genetic Counselors have recently defined guidelines concerning genetic counseling and testing for AD (Goldman et al., 2011). Tests for genes associated with early onset AD (currently APP, PSEN1, and PSEN2) are useful for: (1) symptomatic patients with early onset $\mathrm{AD}$; (2) individuals with a family history of dementia with one or more cases of early onset AD; (3) individuals with a relative affected by a known mutation of $A P P, P S E N 1$, or PSEN2.

In summary, $\mathrm{AD}$ genetic risk factors may be divided into: (1) rare autosomal dominant mutations (APP, PSEN1, PSEN2) genetic tests available in selected circumstances; (2) common mutations with moderate effect $(A P O E)$ - genetic testing not recommended at present due to limited clinical utility and poor predictive value; (3) common mutations with small effect (e.g., CLU, PICALM, CR1, BIN1, ABCA7, MS4A6A, MS4A4E, CD2AP, $C D 33$, and $E P H A 1$ ) - genes with poor predictive value individually.

Genetic counseling is essential during the process of genetic testing for both symptomatic and asymptomatic patients. Pediatric testing is not recommended (Goldman et al., 2011).

\section{NON-GENETIC RISK FACTORS}

$\mathrm{AD}$ is a multifactorial disorder, whose causes remain largely unknown. Despite extensive research on genetic factors, the vast majority of $\mathrm{AD}$ cases are not directly linked to them. Instead, a complex association between environmental or lifestyle and polygenetic factors seems to play a crucial role in sporadic AD vulnerability (Launer, 2002; Murray et al., 2011).

Aging is, by far, the most well established risk factor for the development of sporadic AD. Several studies are unanimous in showing an exponential growth in incidence rates between the 
ages of 65 and 85 years, doubling every 5 years, and no gender differences in the AD incidence (Launer et al., 1999; Fratiglioni et al., 2000; Kawas and Corrada, 2006). In contrast, after the age of 85, the cumulative risk for developing $\mathrm{AD}$ seems to decrease only in men. Thus, the female gender is often associated with a higher relative risk of $\mathrm{AD}$ (Andersen et al., 1999; Ruitenberg et al., 2001).

Modifiable risk factors have received increasing attention. Epidemiological and clinical studies suggest that vascular and metabolic disorders are important risk factors for AD. Growing evidence has emerged suggesting that raised blood pressure (Qiu et al., 2006) and high levels of serum cholesterol (Kivipelto et al., 2005), particularly at adult age, may precede and increase the risk of dementia, including $\mathrm{AD}$, in late life. The biological pathway linking long-standing hypertension or hypercholesterolemia to $\mathrm{AD}$ pathology can be mediated by atherosclerotic lesions and other vascular changes. These lead to chronic or episodic cerebral hypoperfusion and may converge to initiate or accelerate selective neurodegenerative processes in the aging brain, particularly in genetically susceptible hosts (Iadecola and Gorelick, 2003; de la Torre, 2004; Qiu et al., 2006). The hypercholesterolemia's effects in $\mathrm{AD}$ incidence may also be due to an increased synthesis of $\mathrm{A} \beta_{42}$, through modulation of the cleavage pattern of APP, or to interference with the transport and metabolism of this peptide (Kuller and Lopez, 2011). Cardiovascular disease and carotid artery stenosis are strong risk factors, supporting the view that chronic cerebral hypoperfusion may promote selective neurodegenerative damages in susceptible brain areas (Ruitenberg et al., 2005) and suggesting that peripheral atherosclerosis biomarkers can be early indicators of a subclinical phase of AD (Qiu et al., 2006; Muller et al., 2007). Cerebrovascular disease is an important pathological mechanism adding severity to AD (Knopman, 2006). Similarly to hypertension, overweight and obesity initiated at adulthood seem to increase the susceptibility for $\mathrm{AD}$ (Kivipelto et al., 2005), possibly through vascular dysfunction or through the effects of hormonal compounds that are secreted by the adipose tissue (Gustafson, 2006). Diabetes and impaired glucose tolerance have also been associated with increased odds of dementia (Biessels et al., 2006; Qiu et al., 2007). The direct effect of glucose-mediated toxicity and hyperinsulinemia on amyloid metabolism and $\mathrm{AD}$ neurodegenerative processes has been emphasized (Biessels et al., 2006), but the exact pathophysiological mechanisms remain unclear.

The vascular hypothesis suggests that midlife vascular risk factors and disorders are involved in neurodegeneration, progression and clinical presentation of $\mathrm{AD}$. The view that sporadic $\mathrm{AD}$ is primarily a vascular disease with neurodegenerative consequences (de la Torre, 2010) remains controversial, given that both cerebrovascular disease and $\mathrm{AD}$ are very prevalent in the elderly, and thus may coexist in an important proportion of patients. Furthermore, the identification of "pure forms" of AD, i.e., without simultaneous vascular disease, does not support a direct relationship between vascular disease and AD (Román and Royall, 2004).

Concerning tobacco smoking, conflicting outcomes have been reported. Contradicting previous reports, recent studies have found that current smoking is associated with increased risk of AD in older people (Cataldo et al., 2010). With regard to alcohol intake, the outcomes are also controversial, but suggest that light to moderate consumption may decrease the risk of dementia, when compared to abstinence or heavy drinking, in a J-shaped relationship (Xu et al., 2009).

Additional risk factors have been suggested, including migraine (Tyas et al., 2001), high intake of saturated fat (Luchsinger and Mayeux, 2004), high serum homocysteine (Kalmijn et al., 1999) and fibrinogen concentrations (Bots et al., 1998), peripheral inflammation (Engelhart et al., 2004), atrial fibrillation (Duron and Hanon, 2010) and head injury (Guo et al., 2000).

In the elderly population, studies show a strong inverse association between the levels of mental, social and physical activity and the dementia risk (Wang et al., 2002; Rovio et al., 2005). The potential pathway explaining the effects of lifestyle factors on $\mathrm{AD}$ risk can be explained by the cognitive reserve hypothesis, which states that educational or occupational stimulation may lead to a more effective and flexible use of brain networks, resulting in an increase of cognitive functional reserve against brain pathology or age-related changes. Thus, stimulating environments and physical exercise can be protective factors and may modulate the threshold of clinical expression of AD pathology (Fratiglioni et al., 2004; Stern, 2006).

\section{EPIDEMIOLOGY}

$\mathrm{AD}$ is the most common cause of dementia (Fratiglioni et al., 2000; Lobo et al., 2000). By 2005, the Delphi study estimated that there were 24.3 million people worldwide with dementia, with 4.6 million new cases arising every year. Among regional populations of individuals aged $\geq 60$ years, those from North America and Western Europe exhibited the highest prevalence of dementia ( 6.4 and $5.4 \%$, respectively), followed by those from Latin America (4.9\%), China and developing Western Pacific (4.0\%) and Eastern Europe (3.8-3.9\%). The annual regional dementia incidence rates (per 1.000 individuals) were estimated to be 10.5 for North America, 9.2 for Latin America, 8.8 for Western Europe, 8.0 for China and developing Western Pacific and 7.7-8.1 for Eastern Europe. It has been calculated that the number of people with dementia may rise to 81.1 million by 2040 (Ferri et al., 2005).

The estimated lifetime risk of $\mathrm{AD}$ is $10-11 \%$ in males and 14$17 \%$ in females at the age of 85 (Genin et al., 2011). Women bear most of the burden of AD probably due to longer life expectancy and longer post-diagnosis survival duration. However, reports of the association between gender and $\mathrm{AD}$ have been controversial and its unclear whether women have a survival advantage or not (Heyman et al., 1996; Lapane et al., 2001; Brookmeyer et al., 2002; Larson et al., 2004; Helzner et al., 2008; Xie et al., 2008). In some studies, age-specific incidence of AD and prevalence controlled for age do not differ significantly by gender (Hebert et al., 2001). Interestingly, a study reported that $\mathrm{AD}$ pathology is more likely to be clinically expressed as dementia in women than in men (Barnes et al., 2005).

The prevalence and incidence rates for $\mathrm{AD}$ increase exponentially with age. $\mathrm{AD}$ rates rise from 2.8 per 1000 person-years in the age group 65-69 years to 56.1 per 1000 person-years in the older than 90-year age group (Kukull et al., 2002).

$\mathrm{AD}$ substantially reduces life expectancy and increases the probability of being admitted to a nursing home. The median survival times after diagnosis range from 8.3 years for individuals diagnosed with $\mathrm{AD}$ at the age of $65-3.4$ years for persons diagnosed 
as having $\mathrm{AD}$ at the age of 90 . Diagnoses of $\mathrm{AD}$ at ages 65 and 90 years are associated with approximately a 67 and $39 \%$ reduction in median life span, respectively (Brookmeyer et al., 2002). Death from all causes by the age of 80 is expected in $61 \%$ of $\mathrm{AD}$ patients and in $30 \%$ of the general population. Nursing home admission by the age of 80 years is expected for $\sim 75 \%$ of the surviving $\mathrm{AD}$ patients, and only for $4 \%$ of the general population (Arrighi et al., 2010).

\section{DIAGNOSIS}

The clinical diagnosis of dementia caused by AD can approach an accuracy rate of $95 \%$, but only when it is established by highly experienced clinicians observing selected patients who are generally followed up comprehensively over time. Outside of specialized centers, AD dementia is correctly diagnosed only in about $50 \%$ of affected individuals (Mayeux et al., 2011). Accurate diagnosis of $\mathrm{AD}$ is difficult because of the frequent presence, in older adults, of co-morbidities that can contribute to cognitive impairment. A factor that may further complicate diagnosis is ignorance of the patient's previous baseline, which precludes the clinician from correctly evaluating whether there was cognitive and functional decline (a requisite incorporating MCI and dementia criteria) or not. There may not always be a reliable informant and self-reported estimates of function can be inaccurate (Mayeux et al., 2011).

The diagnosis of $\mathrm{AD}$ is frequently based on the criteria of the Diagnostic and Statistical Manual of Mental Disorders, fourth edition (DSM-IV-TR; American Psychiatric Association, 2000) and on the National Institute of Neurologic and Communicative Disorders and Stroke-Alzheimer Disease and Related Disorders Association (NINCDS-ADRDA) criteria (McKhann et al., 1984). Both sets of criteria require deficits in memory and at least one other cognitive domain. The DSM-IV-TR criteria additionally stipulate that there must be an impact of the cognitive impairment on social function or activities of daily living (ADL). According to the NINCDS-ADRDA criteria, the AD diagnosis is classified as definite (clinical diagnosis with histologic confirmation), probable (typical clinical syndrome without histologic confirmation), or possible (atypical clinical features but no alternative diagnosis apparent; no histologic confirmation). The NINCDS-ADRDA criteria have been reasonably reliable for the diagnosis of probable AD: across more than a dozen clinical-pathological studies, they have had a sensitivity of $81 \%$ and a specificity of $70 \%$ (Knopman et al., 2001).

However, using the DSM-IV-TR and the 1984 NINCDSADRDA recommendations, the $\mathrm{AD}$ cases are discovered late in the disease process. Therefore, substantial efforts have been made to create criteria for the clinical stage preceding dementia, i.e., mild cognitive impairment (MCI; Petersen and Negash, 2008), a state in which, by definition, ADL are essentially normal. Nevertheless, MCI is a heterogenous entity, encompassing not only AD cases, but also patients with degenerative diseases other than AD and individuals with non-degenerative causes of cognitive impairment. This issue was solved with the creation of the concept of prodromal $\mathrm{AD}$, which may be considered a subtype of MCI, by Dubois et al. (2007). The core principle of the research criteria for the diagnosis of AD proposed by this group (Dubois et al., 2007) is based upon the presence of consistent episodic memory disturbance which, together with biomarker positivity, recognizes $\mathrm{AD}$ across the full spectrum of the clinical disease. To fulfill criteria for probable AD, a patient must meet the cornerstone clinical criterion $\mathrm{A}$ and at least one of the supportive biomarker criteria. Criterion A specifies that there must be an episodic memory deficit within test conditions of encoding specificity. The presence of a biological footprint of the disease is established either by criterion B (structural imaging), criterion C (cerebrospinal fluid), criterion D (molecular imaging), or criterion $\mathrm{E}$ (dominant mutation within the immediate family). Apart from the incorporation of biomarkers, two relevant innovations characterize the Dubois criteria: (1) the presence of a progressive memory deficit is considered sufficient to make a diagnosis of $\mathrm{AD}$, even if it is the patient's only cognitive deficit; (2) the declarative memory impairment necessary for diagnosis is of the "medial temporal lobe type" (Carlesimo et al., 2011).

In 2011, the NIA-AA workgroup published recommendations concerning the definition of the preclinical stages of AD (Sperling et al., 2011), the diagnosis of MCI due to AD (MCI-AD; Albert et al., 2011) and the diagnosis of dementia due to AD (AD dementia; McKhann et al., 2011), which also integrated biomarker information. According to the NIA-AA workgroup, the major AD biomarkers can be divided into those related to the process of brain $\mathrm{A} \beta$ protein deposition, comprising low cerebrospinal fluid (CSF) $\mathrm{A} \beta_{42}$ and positive positron emission tomography (PET) amyloid imaging, and those related to downstream neuronal degeneration or injury: elevated CSF tau, both total tau (t-tau) and phosphorylated tau ( $\mathrm{p}$-tau); decreased 18fluorodeoxyglucose (FDG) uptake on PET in the temporo-parietal cortex; and disproportionate atrophy on structural magnetic resonance imaging (MRI) in medial, basal and lateral temporal lobe, and medial parietal cortex; McKhann et al., 2011).

According to the NIA-AA recommendations (Albert et al., 2011), in the presence of a change in cognition, objective impairment in at least one cognitive domain, preservation of independence in ADL (and inherent absence of dementia), clinical syndrome suggestive of $\mathrm{AD}$ and examination of potential causes consistent with $\mathrm{AD}$, an individual is classified as having MCI-ADcore clinical criteria in the following situations: (1) in the absence of information on biomarkers; (2) in the event that they are uninformative (neither clearly negative nor positive); or (3) in the case that their information is conflicting (e.g., low A $\beta$ and normal tau in CSF). The "suggestive" clinical syndrome involves typically a prominent impairment in episodic memory, but other patterns, such as visuo-spatial impairment, are also possible manifestations of underlying $\mathrm{AD}$ pathology and, as such, are compatible with a diagnosis of MCI-AD. A subject is attributed a diagnosis of MCI$\mathrm{AD}$ with intermediate likelihood if he has one positive biomarker either reflecting $A \beta$ deposition or neuronal injury. A person is diagnosed with MCI-AD with a high likelihood if both biomarkers are positive. An individual is attributed a diagnosis of MCI unlikely due to $\mathrm{AD}$ if both biomarkers are negative.

Regarding AD dementia, the NIA-AA workgroup (McKhann et al., 2011) proposes the following terminology: (1) probable AD dementia, (2) possible $\mathrm{AD}$ dementia, (3) probable or possible $\mathrm{AD}$ dementia with evidence of the $\mathrm{AD}$ pathophysiological process. The first two concepts are intended for use in all clinical settings. The third is to be used for research purposes only. The authors underline that dementia from all causes implies the presence of 
cognitive decline from previous levels of performance, detected by history taking and objective assessment, involving a minimum of two domains, interfering with ADL and not explained by delirium or major psychiatric disorder. According to McKhann et al. (2011), probable $\mathrm{AD}$ dementia is diagnosed when the patient meets criteria for dementia and, in addition, there is clear-cut history of worsening of cognition by report or observation, insidious onset, and the initial and most prominent cognitive deficits are in one of the following categories: memory, language, visuo-spatial function, or executive function. The NIA-AA workgroup recommends that the diagnosis of probable $\mathrm{AD}$ dementia should not be applied when there is evidence of substantial concomitant cerebrovascular disease, core features of Dementia with Lewy bodies (DLB; other than dementia itself), prominent features of fronto-temporal lobar degeneration (FTLD), evidence of another concurrent, active neurological disease, or of a non-neurological medical comorbidity or use of medication that could have a substantial effect on cognition. In persons who meet the core clinical criteria for probable $\mathrm{AD}$ dementia, the authors (McKhann et al., 2011) postulate an increased level of certainty of diagnosis in the presence of: documented decline and/or causative AD genetic mutation. According to the same workgroup, a diagnosis of possible $\mathrm{AD}$ dementia is made when there is an atypical course, that is, when there is sudden onset of cognitive impairment, or insufficient historical detail or objective cognitive documentation of progressive decline, or when there is an etiologically mixed presentation.

McKhann et al. (2011) state that, in persons who meet the core clinical criteria for probable $\mathrm{AD}$ dementia, biomarker evidence may increase the certainty that the basis of the clinical dementia syndrome is the AD pathophysiological process. However, the authors do not advocate the use of AD biomarker tests for routine diagnostic purposes at the present time. They indicate the reasons for this limitation: the very good diagnostic accuracy of the core clinical criteria; the need for more research validating the design of the biomarker incorporating criteria; the limited standardization of biomarkers from one site to another; and the limited access to biomarkers in many community settings.

\section{AD VARIANTS}

Typically, AD presents with initial episodic memory dysfunction, followed by progressive involvement of other cognitive domains, including praxis, visuo-spatial orientation, language, calculation and executive functions. Deficit progression mirrors the successive involvement of different brain regions, beginning with hippocampal damage and spreading to lateral temporal regions, parieto-occipital cortex and frontal lobe structures. However, AD pathology is also found in patients presenting with different clinical symptoms, caused by initial damage on less frequently involved cortical regions. These atypical cases pose diagnostic difficulties, and are frequently identified as non-AD cases, including FTLD, Lewy-body disease (LBD) and cortico-basal degeneration (CBD), in which non-memory deficits are more frequent. Atypical AD patients present in at least two different patterns. The syndrome of posterior cortical atrophy (PCA) involves dysfunction of the visuospatial areas of the occipital and parietal cortices. Primary progressive aphasia (PPA) affects almost exclusively language related structures.
The PCA syndrome, first described by Benson et al. (1988), is characterized by the early appearance (before the age of 60) of alexia with agraphia (the most frequent symptoms, which occur without significant derangement of other language related functions), Balint's syndrome (optic ataxia, ocular apraxia, simultanagnosia, and visual agnosia) and Gerstmann syndrome, with acalculia as the predominant symptom (Galton et al., 2000; TangWai et al., 2004; McMonagle et al., 2006; Alladi et al., 2007). Some cases present with predominant parietal dysfunction (involving the dorsal stream of visual perception - the where stream), manifested by agraphia and apraxia, and others show occipital dysfunction (involving the ventral stream - the what stream), expressed by symptoms of visual agnosia, prosopagnosia, achromatopsia and alexia. A third PCA group has been suggested, consisting of patients with cortical blindness, caused by degeneration of the occipital primary visual cortex (Galton et al., 2000). MRI studies have shown atrophy in regions related to the cognitive deficits found on neuropsychological evaluation, and relative preservation of temporal mesial regions. However, not all cases show conspicuous atrophy on MRI. Functional imaging shows hypofunction of the regions responsible for the cognitive deficits. Many cases evolve to full-blown dementia, including affection of episodic memory and other cognitive domains. Nevertheless, some patients maintain exclusive derangement of posterior cortical functions for many years, and some die without presenting the complete late stage AD pattern (Galton et al., 2000; Alladi et al., 2007). Although PCA is defined as a syndrome, caused by different diseases that affect the posterior cortex (including LBD, prion diseases and $\mathrm{CBD}$ ), neuropathological examination shows a marked predominance of AD cases (Renner et al., 2004). Renner et al. (2004) were not able to find clinical differences between $\mathrm{AD}$ and non-AD PCA cases, although some LBD patients would eventually develop the visual hallucinations and extra-pyramidal symptoms characteristic of the disease (Tang-Wai et al., 2004; McMonagle et al., 2006). AD parietal atrophy cases were also difficult to differentiate from CBD cases.

Primary progressive aphasia was first described by Mesulam as a syndrome consisting of progressive deterioration of language and preservation of other cognitive functions, associated with left temporal and frontal lobe atrophy (Mesulam, 2001). As these cases were primarily associated with the FTLD spectrum of diseases, the existence of early language deficits was usually considered as an exclusion criteria for AD. Further investigation has revealed that $\mathrm{AD}$ could underlie a higher percentage of PPA cases than was first considered. The syndrome of primary aphasia was classically divided into two distinct patterns: non-fluent aphasia and semantic dementia. Recently, a third pattern was proposed, consisting of patients who seem to share deficits belonging to the other categories: slow speech and word finding difficulties (as in non-fluent aphasia), with preservation of grammar and phonological functions and presence of deficits in naming (similar to semantic dementia). Difficulty in sentence repetition and in understanding long sentences, with preserved ability to understand single words are also characteristic. This particular kind of PPA, named logopenic aphasia, has been linked by imaging and functional studies to atrophy of the left temporo-parietal junction, including the left posterior superior and middle temporal gyri 
and inferior parietal lobule (Henry and Gorno-Tempini, 2010). $\mathrm{AD}$ pathology could be present in about $20-30 \%$ of patients with PPA. Interestingly, it appears to be linked with particular types of PPA. While atypical Alzheimer cases rarely present with semantic and non-fluent aphasia, $\mathrm{AD}$ pathology appears to be common in logopenic patients, as proven by clinical-pathological studies (Alladi et al., 2007; Mesulam et al., 2008) and by imaging studies using Pittsburgh compound B (PiB; Rabinovici et al., 2008).

A frontal variant of $\mathrm{AD}$ has also been reported, characterized by prominent executive and behavioral symptoms, mimicking the behavioral variant of FTLD, but presenting with AD pathology and selective deposition of amyloid in frontal regions (Johnson et al., 1999; Alladi et al., 2007). These findings have not been replicated in other studies, and the existence of this variant remains controversial.

The prevalence of $A D$ atypical variants is unknown. In the study by Galton et al. (2000), atypical cases represented $14 \%$ of all $\mathrm{AD}$ cases followed in the institution. This was, however, a tertiary center of referral, in which atypical cases could be over-represented. In the mentioned study, PCA was present in 6 out of 26 atypical cases, while 20 had the aphasic variant (Galton et al., 2000). Little is known about the relative predominance of $\mathrm{AD}$ pathology in the total number of patients presenting with focal cortical symptoms, as compared to FTLD, DLB, and CBD pathology. In a study performed in 100 patients with focal cortical syndromes, $\mathrm{AD}$ was present in all PCA cases and in more than half of the mixed aphasic cases (a group which included patients with the logopenic variant). Half of the cortical basal syndrome (CBS) cases, about $40 \%$ of the patients with the non-fluent aphasia syndrome and a small percentage with behavioral FTLD and semantic dementia syndromes had AD pathology (Alladi et al., 2007). This suggests that, while a diagnosis of PCA represents a high probability of AD, symptoms characteristic of FTLD (particularly the progressive non-fluent aphasia type) or CBS should not rule out this diagnosis.

\section{FIRST APPROACH TO THE PATIENT}

The European Federation of Neurological Societies (EFNS) guidelines for the diagnosis and management of AD (Hort et al., 2010) recommend that the evaluation of a subject suspected of having $\mathrm{AD}$ should include history, from the patient and a close informant, focused on the affected cognitive domains, the course of the illness, the impact on the ADL and any associated non-cognitive symptoms.

Global assessment of cognitive functions should be undertaken, using, for example, Mini-Mental State Examination (MMSE; Folstein et al., 1975). Such a screening test is useful for the identification of cases requiring more detailed evaluation. This is done using neuropsychological tests assessing memory, executive functions, language, praxis and visuo-spatial abilities (Hort et al., 2010).

As the differentiation of dementia from MCI rests on the determination of whether or not there is significant interference in the ability to function at work or in usual daily activities, it is useful to assess ADL. However, there is no gold standard available for this purpose (Hort et al., 2010). In a review by Sikkes et al. (2009), out of several systematically reviewed scales, the informant-based questionnaires the Disability Assessment for Dementia and the Bristol ADL were among the most useful. The AD8, a brief informant-based questionnaire that is able to differentiate between non-demented and demented individuals in a trustworthy manner (Galvin et al., 2005), is also helpful.

Behavioral and psychological symptoms, as well as co-morbid conditions, should be identified, since they occur in the majority of $\mathrm{AD}$ patients and are associated with decline in cognitive and functional ability (Apostolova and Cummings, 2008), decreased quality of life and increased institutionalization (Hort et al., 2010).

Hort et al. (2010) also consider important to elicit past medical history, co-morbidities, family and educational history. It is stressed that neurological and general physical examination are helpful in distinguishing $\mathrm{AD}$ from other primary degenerative and secondary dementias and co-morbidities.

Blood tests, according to the EFNS guidelines (Hort et al., 2010), are useful in excluding co-morbidities and should include vitamin B12, folate, thyroid stimulating hormone, calcium, glucose, complete blood cell count, renal and liver function. Syphilis, Borrelia and HIV serological tests should be considered in high risk cases or when there are suggestive clinical features.

Structural brain imaging is useful in excluding potentially surgically treatable diseases and in detecting specific findings for $\mathrm{AD}$. For the former, CT and MRI are similarly good and it is consensual that such an imaging procedure should be carried out once in every patient. However, MRI is more sensitive to subtle vascular changes and to alterations specific of certain conditions. For practice purposes, a standard MRI protocol involving at least coronal $\mathrm{T} 1$ and axial T2 or fluid-attenuated inversion recovery sequences should be used (Hort et al., 2010).

Electroencephalography (EEG) may help to differentiate between $\mathrm{AD}$, subjective complaints and psychiatric diagnoses. EEG can also be useful in the differential diagnosis of atypical clinical presentations of AD. Even though reduced alpha power, increased theta power and lower mean frequency are characteristic of $\mathrm{AD}$ patients, EEG can be normal early in the course of the disease in up to $14 \%$ of cases (Hort et al., 2010).

\section{NEUROPSYCHOLOGICAL EVALUATION}

Episodic memory should be assessed because it is the function most commonly impaired early in $\mathrm{AD}$ as a result of dysfunction of mesial temporal structures, which are responsible for consolidation. Retrieval, which depends on frontal lobe and subcortical structures, is less affected (Hort et al., 2010).

Impaired delayed recall is not, per se, evidence of an $\mathrm{AD}$-related memory disorder. Authentic deficits in encoding and storage processes (features typical of $\mathrm{AD}$ ) must be differentiated from non-AD deficits that can also affect delayed recall, including attentional difficulties, which may be present in depression, and inefficient retrieval strategies, associated with normal aging, FTLD, or subcortical-frontal dementias (Dubois et al., 2007).

Dubois et al. (2007) proposed the use of a neuropsychological tool - the Grober-Buschke (GB) paradigm (Grober et al., 1988) which, controlling for elaborative encoding at study and providing a strong category cue at retrieval, should be able to compensate for eventual encoding/retrieval deficits and allow to identify the memory impairment that is caused by reduced efficiency of consolidation of the memory trace (Carlesimo et al., 2011). Within this neuropsychological test paradigm, measures of sensitivity to semantic cueing can successfully differentiate patients with $\mathrm{AD}$ from healthy controls (Dubois et al., 2007). 
Sarazin et al. (2007) found that the most sensitive and specific test for diagnosis of prodromal AD was the Free and Cued Selective Recall Reminding Test (FCSRT; Grober and Buschke, 1987). Their study showed that impairment of free recall, total recall, and index of sensitivity of cueing can identify prodromal AD in patients with MCI with high sensitivity (79.7\%) and specificity (89.9\%).

In a series of studies reviewed by Carlesimo et al. (2011), total immediate recall scores on the original or modified version of the GB paradigm achieved levels of sensitivity between 62 and 100\% and of specificity between 93.9 and $100 \%$ in the discrimination between $\mathrm{AD}$ and healthy elderly individuals. However, none of these studies verified the diagnosis of $\mathrm{AD}$ using a postmortem histologic examination.

On the other hand, the review by Carlesimo et al. (2011) did not completely corroborate the superiority of the GB paradigm over more traditional neuropsychological tools for analyzing memory disorders in patients suspected of having AD. In fact, controversial results emerged from studies that compared the sensitivity/specificity of the cued recall task in the GB paradigm with the free recall task in the same or a different experimental paradigm in differentiating patients with full-blown AD or amnestic MCI from healthy individuals. The authors (Carlesimo et al., 2011) concluded that the GB procedure was useful for discriminating whether an isolated memory deficit in an elderly person is due to incipient $\mathrm{AD}$ or to other causes and for helping in the differential diagnosis between $\mathrm{AD}$ and other etiological forms of dementia.

In an interesting study involving 150 patients with an objective history of episodic memory dysfunction (Oksengard et al., 2010), it was found that delayed recall, objectively assessed by Rey Auditory Verbal Learning Test (RAVLT; Rey, 1958), was the most sensitive marker in the detection of AD cases, when compared with MRI, single photon emission tomography (SPECT), CSF t-tau, $A \beta_{42}$, and p-tau.

\section{BIOMARKERS \\ MAGNETIC RESONANCE IMAGING}

Atrophy of the medial temporal lobe atrophy (MTA) is a wellrecognized feature of $\mathrm{AD}$, though there are limitations concerning its specificity, because marked hippocampal atrophy has also been shown in fronto-temporal dementia (Galton et al., 2001), dementia with Lewy bodies (DLB; Barber et al., 2000), Parkinson's disease with dementia (Tam et al., 2005), vascular dementia (Barber et al., 2000) and hippocampal sclerosis (Barkhof et al., 2007). However, only one of these studies was in autopsy-confirmed cases (Barkhof et al., 2007) and thus misdiagnosis cannot be ruled out. Indeed, at least two clinical-pathological studies showed high sensitivity and specificity rates in the discrimination between $\mathrm{AD}$ and non-AD dementias.

Burton et al. (2009) assessed the diagnostic specificity of MTA, rated visually on MRI using a standardized scale (Scheltens et al., 1992), blind to clinical or autopsy diagnosis, for AD among individuals with AD, DLB and vascular cognitive impairment (VCI). The study group consisted of 46 individuals who had both antemortem MRI and an autopsy. Subjects were pathologically classified as AD, DLB, or VCI. MTA was a highly accurate diagnostic marker for autopsy-confirmed AD (sensitivity of $91 \%$ and specificity of $94 \%$ ).
Vemuri et al. (2011) created atrophy maps using structural MRI and applied them for classification of new incoming patients. They identified 115 pathologically confirmed subjects with a single dementing pathologic diagnosis (AD, LBD or FTLD-TDP-43) who had an MRI at the time of clinical diagnosis of dementia. Leaveone-out classification showed reasonable performance compared to the autopsy "gold standard": in AD, sensitivity was $90.7 \%$ and specificity $84 \%$.

A recent study (Karow et al., 2010) showed no evidence that brain FDG PET was more sensitive than MRI to the degeneration occurring in preclinical and mild AD. Thus, MRI, a practical exam, might be used instead of more sophisticated ancillary tests in clinical practice for early detection of AD.

New quantitative methods using MRI are promising biomarkers. These include: functional MRI and diffusion tensor imaging (Hampel et al., 2008); diffusion weighted imaging, magnetization transfer MRI and proton magnetic resonance spectroscopy (Kantarci and Jack, 2003); and MR volumetry methods. The latter encompass cortical thickness measurement, deformation-based and voxel-based morphometry (Hampel et al., 2008), as well as multiple-atlas propagation and segmentation technique (Leung et al., 2010).

\section{SINGLE PHOTON EMISSION TOMOGRAPHY}

The EFNS guidelines (Hort et al., 2010) considered that SPECT could increase diagnostic confidence in the evaluation of dementia. However, and even though it is more widely available and cheaper than PET, it was not included in the Dubois criteria (Dubois et al., 2007), because of its poor estimated diagnostic accuracy. It is not mentioned in the recommendations from the NIA-AA workgroup (McKhann et al., 2011), either.

Pooling data in an exploratory manner from two clinicalpathological studies, Dougall et al. (2004) found a weighted sensitivity for a "positive" brain SPECT (that is, one showing a pattern of bilateral temporo-parietal hypoperfusion) of $74 \%$ and a weighted specificity of $91 \%$ against neuropathology. In theses studies using pathological verification as a gold standard, clinical criteria were more sensitive than brain SPECT (81 versus 74\%) and brain SPECT had a higher specificity than clinical criteria (91 versus $70 \%$ ).

In the context of other clinical-pathological study, by Jagust et al. (2001), the clinical diagnosis of probable AD was associated with an $84 \%$ likelihood of pathologic AD. A positive perfusion SPECT scan raised this likelihood to $92 \%$, whereas a negative SPECT scan lowered it to $70 \%$. SPECT was more useful when the clinical diagnosis was possible $\mathrm{AD}$, with a likelihood of $67 \%$ without SPECT, increasing to $84 \%$ with a positive SPECT, and decreasing to $52 \%$ with a negative SPECT.

Dopaminergic SPECT imaging is useful to differentiate AD from DLB with sensitivity and specificity around 85\% (Hort et al., 2010).

\section{POSITRON EMISSION TOMOGRAPHY FDG PET}

In vivo brain FDG PET is a minimally invasive diagnostic imaging procedure used to evaluate cerebral glucose metabolism. The pattern of metabolic impairment of the posterior cingulate 
and temporo-parietal cortices, including the precuneus, more accentuated than frontal cortex deficits, together with relative preservation of the primary sensorimotor and visual cortices, basal ganglia, and cerebellum, constitutes the distinctive metabolic phenotype of AD (Bohnen et al., 2012).

Hoffman et al. (2000) studied FDG PET imaging in individuals with difficult-to-characterize memory loss or dementia who eventually received pathologic confirmation of diagnosis. The sensitivity, specificity, and diagnostic accuracy of bilateral temporoparietal hypometabolism being associated with $\mathrm{AD}$ were 93, 63, and $82 \%$, respectively.

In a study by Silverman et al. (2001), using neuropathological diagnosis as "gold standard," PET was 94\% sensitive and 73\% specific in identifying AD.

According to a study by Minoshima et al. (2001), PET could distinguish autopsy-confirmed AD and DLB patients with $90 \%$ sensitivity and $80 \%$ specificity.

Another study, by Jagust et al. (2007), reported results of a mixed sample of subjects with variable levels of cognitive impairment, who eventually underwent autopsy. Results showed that PET had sensitivity of $84 \%$ and specificity of $74 \%$ for the pathologic diagnosis of AD. The clinical diagnosis of $\mathrm{AD}$ was associated with a $70 \%$ probability of detecting $\mathrm{AD}$ pathology; with a positive PET scan this increased to $84 \%$, and with a negative PET scan this decreased to $31 \%$. A diagnosis of "not AD" at initial clinical evaluation was associated with a $35 \%$ probability of $\mathrm{AD}$ pathology, increasing to $70 \%$ with a positive PET scan. The probability of a postmortem diagnosis of $\mathrm{AD}$ for an initial normal cognitive assessment and negative FDG PET findings was $17 \%$.

In a study by Foster et al. (2007), involving patients with pathologically confirmed AD or FTLD, adding FDG PET to clinical information increased the accuracy of AD diagnosis from 86 to $97 \%$.

\section{PiB PET}

$N$-methyl-11C-2-(4-methylaminophenyl)-6-hydroxybenzothiazole, also known as $11 \mathrm{C}-6-\mathrm{OH}-\mathrm{BTA}-1$ or $11 \mathrm{C}-\mathrm{PiB}$, is an amyloidbinding PET tracer.

The topological pattern of $\mathrm{PiB}$ binding in preclinical and clinical AD patients comprises prefrontal cortex (PFC), medial parietal cortex, lateral temporal cortex, striatum and posterior cingulate cortex (PCC), with PFC being the region with earliest and most pronounced uptake (Prvulovic and Hampel, 2011).

The diagnostic sensitivity of $\mathrm{PiB}$ to accurately classify $\mathrm{AD}$ patients and control subjects is reported to average approximately 90\% (Prvulovic and Hampel, 2011).

Devanand et al. (2010) evaluated 11C-PiB regional binding potential (BPND, cerebellar reference) in individuals with clinical diagnosis of mild AD, MCI and controls. Using a precuneus BPND cut-point of 0.4087 (values above this considered abnormal), in the differentiation of AD from controls, sensitivity was 0.944 and specificity 0.944. In distinguishing MCI from controls, sensitivity was 0.273 and specificity 0.944 .

A puzzling fact is that $10-30 \%$ of asymptomatic healthy elderly subjects have increased $\mathrm{PiB}$ uptake, a finding that is consistent with several autopsy studies which found AD-typical neuropathological changes in a similar fraction of cognitively intact elderly individuals. On the other hand, a small fraction of $\mathrm{AD}$ patients do not show any increase in $\mathrm{PiB}$ uptake, which may be explained by inaccurate clinical diagnosis or the fact that $\mathrm{PiB}$ does not bind to all fibrillar $\mathrm{A} \beta$ conformations (Prvulovic and Hampel, 2011).

\section{CSF ANALYSIS}

The typical CSF pattern of AD consists of decreased levels of $A \beta_{42}$ and increased values of $t$-tau or $p$-tau. Studies show that CSF A $\beta_{42}$ changes before total tau (Isaac et al., 2011).

In a multicenter-study, CSF baseline concentrations of p-tau predicted conversion to $\mathrm{AD}$ in subjects with MCI with high accuracy $(80 \%)$ during an observation interval of 1.5 years (Ewers et al., 2007; Prvulovic and Hampel, 2011).

A prospective cohort study (Visser et al., 2009) found that the CSF AD profile could identify patients with potential AD type dementia among patients with MCI at sensitivities in the range of 88-91\% and specificities between 52 and 90\%.

In a large cross-sectional study involving patients with $\mathrm{AD}$, fronto-temporal dementia (FTD) and DLB, CSF concentrations of p-tau-181 discriminated between DLB and AD with a sensitivity of $94 \%$ and a specificity of $64 \%$, while CSF concentrations of p-tau-231 performed particularly well in the separation of $\mathrm{AD}$ and FTD groups, with a sensitivity of $88 \%$ and a specificity of $92 \%$ (Hampel et al., 2004).

Welge et al. (2009) found that combining CSF p-tau with $A \beta_{42} / A \beta_{38}$ resulted in a sensitivity of $94 \%$ for detection of $A D$ and $85 \%$ specificity for excluding non-AD dementias.

In a clinical study by de Souza et al. (2011), the p-tau/A $\beta_{42}$ ratio was the best biomarker for distinguishing $\mathrm{AD}$ from behavioral variant FTLD and SD, with a sensitivity of 91.7 and $98.3 \%$, respectively, and a specificity of 92.6 and $84.2 \%$, respectively.

Le Bastard et al. (2010) investigated the utility of CSF in cases that had clinically ambiguous diagnoses, using autopsy-confirmed dementia diagnosis as gold standard. $\mathrm{AD}$ and non-AD patients showed no significant differences in CSF $A \beta_{42}$ and t-tau concentrations, whereas p-tau (specifically p-tau-181) concentrations were significantly higher in $\mathrm{AD}$ compared to non-AD patients. The biomarker-based diagnostic model correctly classified $82 \%$ of the patients.

Interestingly, in a study by Schoonenboom et al. (2012), CSF AD biomarker profile was seen in $47 \%$ of DLB cases, $38 \%$ of CBD individuals, and in almost $30 \%$ of FTLD and vascular dementia patients. Individuals with psychiatric diseases and with subjective memory complaints had normal CSF biomarkers in 91 and $88 \%$ of cases, respectively.

\section{CANDIDATE BLOOD-BASED BIOMARKERS}

There is evidence of peripheral oxidative damage correlating with the occurrence of AD (Di Domenico et al., 2011). Thus, peripheral oxidative biomarkers might be useful for early diagnosis and prognosis. Complement factor $\mathrm{H}$, alpha-2-macroglobulin, and clusterin have all been consistently associated with Alzheimer's type pathology (Ballard et al., 2011a). Ijsselstijn et al. (2011) identified a significant increase in concentration of pregnancy zone protein $(\mathrm{PZP})$ in pre-symptomatic $\mathrm{AD}$, when compared with controls. At 
present, the use of plasma based $\mathrm{A} \beta$ cannot be recommended as diagnostic biomarker for MCI and AD (Prvulovic and Hampel, 2011).

\section{ROLE OF BIOMARKERS IN THE CLINICAL SETTING}

It is currently difficult to understand the relative importance of different biomarkers when used together, and to interpret results when biomarker data conflict with one another (Albert et al., 2011).

Much work is still needed to determine the sensitivity, specificity, and predictive value of biomarkers for a diagnosis of $\mathrm{AD}$ in clinical samples. On the other hand, $\mathrm{AD}$ biomarkers allow the detection of $\mathrm{AD}$ pathology in living individuals who have no clinically discernible cognitive impairment. Such individuals are considered to have preclinical $\mathrm{AD}$, with the assumption that all eventually will develop symptomatic $\mathrm{AD}$ if they live long enough (Mayeux et al., 2011). However, it is known that some older individuals with the pathophysiological process of AD may not become symptomatic during their lifetime (Sperling et al., 2011). Use of biomarkers in the clinical setting is thus currently unwarranted because many individuals who satisfy the proposed research criteria may not develop the clinical features of $\mathrm{AD}$ in their lifetime (Sperling et al., 2011).

Nevertheless, biomarkers can be used as optional tools when considered appropriate by the clinician (McKhann et al., 2011).

In our view, biomarkers should be used in MCI and demented patients whose characteristics pose doubt as to etiology. The choice of biomarkers depends on local availability and costeffectiveness issues, must take into consideration the time dependence of biomarker changes during disease progression and the main alternative differential diagnosis in the case in question.

\section{PREDICTORS OF RATE OF DISEASE PROGRESSION}

Factors that seem to increase the rate of disease progression (in terms of cognitive and/or functional status) include: higher education (Bruandet et al., 2008; Musicco et al., 2009, 2010; Roselli et al., 2009); younger onset (Musicco et al., 2009; Tschanz et al., 2011); increased baseline severity (Ito et al., 2011); psychosis (Stern et al., 1994; Lopez et al., 1997); extrapyramidal signs (Mortimer et al., 1992; Stern et al., 1994); lower CSF A $\beta 42$ levels, higher tau or p-tau-181 levels, lower p-tau-181/tau ratio and higher tau/A $\beta$ 42 ratios (Kester et al., 2009; Snider et al., 2009).

\section{TREATMENT}

The particular assembly of symptoms that each patient manifests as a result of $\mathrm{AD}$ changes along the course of the disease and is also different between patients. Added to the dynamic influence of co-morbidities and co-medications, this fact may, at least partially, explain why the effect of many treatments may vary both intra and inter individually. Clinical trials, unable to control all variables and limited by the complex task of detecting changes in cognition or behavior, often reflect these heterogeneities by showing a globally small, non-significant or conflicting effect for the treatment they are evaluating (Gauthier et al., 2010). Considering that many drugs (and other treatments) have significant side effects and costs, producing guidelines for the treatment of this disease is not always clear-cut. Despite all this, good level of evidence exists for some effects of a small group of drugs, and for another group of treatments a more or less systematic effect can also be expected, so that it is possible to advise on many aspects of the management of this form of dementia with some degree of certainty (Hort et al., 2010; Ballard et al., 2011a; Massoud and Léger, 2011). Decisions at the level of a single patient, especially in moderate and advanced disease, often have to be, though, based in expert opinions, one's previous experience or extrapolations from other diseases.

The currently available treatments for $\mathrm{AD}$ are symptomatic. They are able to, at least transiently, ameliorate some aspects of cognition and function and reduce some neuropsychiatric symptoms, making patients and their entourage suffer less with the disease. If patients under treatment see their therapies removed after a certain time of continuous administration they will be essentially indistinguishable from patients never treated, meaning that this treatments are not intervening in disease progression.

The measures currently advocated to manage this form of dementia involve adapting the patient's environment and treating the patient himself.

The interaction of a demented patient with the environment around him is dysfunctional. Some measures can reduce the consequences of this (Hort et al., 2010). The continuous education of the caregivers, perhaps starting with setting real expectations as to what to expect in terms of long-term evolution of symptoms and treatment effect, is of primordial importance. The ability of patients to correctly use money, medications, transports and home appliances should be assessed and continuous adaptation of the facilities at home and other pertinent environments should be planned. Ability to drive should also be assessed according to global (Iverson et al., 2010) and country-specific guidelines. Information about social security, legal and other related matters should be systematized. The caregivers should be advised of the possibility of their own exhaustion and strategies to avoid it should be foreseen.

Objectives of intervention in the patient himself can be conceptually divided in two: (transiently) revert some cognitive deficits and ameliorate functional capacity; and revert disturbing neuropsychiatric symptoms or behaviors. These treatments may be pharmacological or non-pharmacological.

The mainstay of treatment consists of a small group of drugs that showed consistent, albeit small and variable, benefits in welldesigned clinical trials. They are the only currently approved treatments for $\mathrm{AD}$ by the authorities of most countries and include the cholinesterase inhibitors (donepezil, rivastigmine, galantamine) and the NMDA receptor antagonist memantine (for a review of the evidence see Herrmann et al., 2011). As stated above for the treatment of AD in general, they show only a "symptomatic" effect, although a neuroprotective potential has also been proposed.

Cholinesterase inhibitors are approved for mild to moderate disease (usually MMSE between 16 and 26), where they proved to have effect in cognition, global outcome and function when compared to placebo (Birks and Harvey, 2006; Loy and Schneider, 2006; Birks et al., 2009). Weaker evidence shows some effect in severe AD (Herrmann et al., 2011) and the FDA has also approved donepezil for moderate to severe disease. These drugs show as well benefit in some neuropsychiatric symptoms, particularly apathy, and somewhat less in psychosis. In clinical practice one can generally expect to observe slight amelioration in cognition and 
stabilization in function, parameters which are presumed to return to baseline or start degrading again after 6 to 12 months of treatment. Differences in drug metabolism may justify switching from one cholinesterase inhibitor agent to another in cases of intolerance or lack of effect (Massoud et al., 2011). The most common side effects are gastrointestinal dysfunction, anorexia and sleep disturbances. They can usually be avoided by titrating up the dose. The most concerning side effects of these medications are bradycardia and syncope, reasons for which it is advisable to evaluate preexisting bradycardia or cardiac conduction blocks with an electrocardiogram and monitor blood pressure. Rivastigmine administered in a transdermal patch has fewer side effects than its oral form, maintaining the same benefits (Winblad et al., 2007).

Memantine is approved for moderate to severe $\mathrm{AD}$, where it proved to have beneficial effects in cognitive performance, function and global measures (McShane et al., 2006). Memantine may also be useful in the prevention and treatment of agitation, aggression, irritability and psychosis. As with cholinergic drugs, one should expect stabilization of cognition and function for 6 months after onset of treatment. Memantine is usually well tolerated. Dose-limiting side effects are rare and consist of dizziness, headache, somnolence, and confusion.

There also seem to be additive benefits of combining a cholinesterase inhibitor and memantine (Tariot et al., 2004; Atri et al., 2008; Lopez et al., 2009) albeit not all studies have supported this (Porsteinsson et al., 2008).

The short duration of most trials with these four drugs precludes us from knowing the time for how long a difference from placebo is maintained. The majority of experts advice caution in stopping these drugs, although some reasons for discontinuation may be advocated (Massoud et al., 2011).

Concerning non-pharmacological approaches to help maintain or enhance the cognitive, functional and global status of these patients, current evidence suggests that cognitive training and cognitive stimulation offer modest, albeit significant, benefits. The results are mainly limited to the cognitive domains on which the intervention is focused and, as these interventions are laborious, cost-effectiveness studies are needed (Ballard et al., 2011b).

Another major topic in the treatment of $\mathrm{AD}$ is the approach to certain frequent and disturbing neuropsychiatric symptoms like apathy, depression, anxiety, psychosis, agitation, irritability, aggression and sleep disturbances. There are no authority approved treatments for these situations, which is a consequence of lack of data, insufficient or conflicting results and concerns with possible side effects. In general terms, non-pharmacological interventions are advocated first (sleep hygiene measures, for instance). When symptoms are very severe and menacing, pharmacological treatment may be started immediately, accompanied by non-pharmacological measures. Another general rule is that drug treatments employed in this setting should be administered in the minimal efficacious dose and envisaged as transitory. Registering all the events prior to these manifestations helps to identify possible environmental triggers.

For depression, when symptoms are mild and transient, nonpharmacological approaches should be tried, like structured activities, such as day programs and daily exercise (Ballard et al., 2008). Bright light therapy can aid sleep and reduce mood and behavioral disturbance (Gauthier et al., 2010). For severe depression, most clinicians use antidepressive drugs, whose efficacy has been shown in many trials, although not in all. Sertraline $(100 \mathrm{mg} /$ day $)$ is the most documented drug, but other SSRI's and other classes can be tried, as long as side effects are considered (Gauthier et al., 2010; Ballard et al., 2011a).

Neuroleptic drugs are commonly used to treat aggression, agitation and psychosis. Efficacy has been demonstrated for risperidone (especially $2 \mathrm{mg}$ /day) when prescribed for aggression, but for agitation and psychosis, and for use of other neuroleptics, results are weak or conflicting. Benefits, which are often moderate, must be weighed against potentially serious adverse events like sedation, parkinsonism, chest infections, ankle edema, and an increased risk of stroke and death. As already stated, minimal effective doses should be used and long-term prescription avoided. Anticonvulsants, like carbamazepine (useful for agitation), and benzodiazepines may be helpful in selected cases. For the first one, potential drug interactions should not be forgotten, and, for the latter, very short term use should be foreseen. Simple non-pharmacological treatments, such as increasing physical and social activity, aroma therapy (lavender and melissa), therapy with animals, music therapy and simulated presence therapy (audio or video tapes with familiars), can be effective alternatives (Ballard et al., 2008, 2011a; Gauthier et al., 2010).

The treatment of $\mathrm{AD}$ also involves management of comorbidities. They often cause sudden aggravation of cognitive deterioration or appearance of neuropsychiatric symptoms. In these situations, so called "medical" causes, such as metabolic and infectious diseases, as well as cerebrovascular pathologies, must be actively sought and treated.

Other symptoms which must be dealt with (mostly in advanced disease stages) include parkinsonism, gait instability, myoclonus, seizures, contractures, pressure ulcers, pain, and undernutrition.

Concerning emerging treatment drugs, they are expected to show less inter-individual variability and a more marked effect. For that purpose, they must act directly in the mechanisms of disease and be administered earlier in the course of AD, before significant neurodegeneration has occurred. Hopefully, biomarkers will allow diagnosis before a dementia syndrome is installed and permit testing drugs at a stage when they could be (more) effective.

Several lines of drug investigation are being pursued, some targeting only symptomatic treatment, but the majority aiming to show a disease-modifying effect (for reviews see Potter, 2010; Herrmann et al., 2011; Salomone et al., 2012).

New cholinergic agents in investigation include direct and allosteric muscarinic acetylcholine receptor agonists and also agonists of certain subtypes of nicotinic receptors.

A group of drugs aiming to reduce $A \beta$ production include: rosiglitazone, which, among other modes of action, could inhibit $\beta$ secretase, was ineffective in a phase 3 trial, despite suggestion of efficacy in earlier data (Gold et al., 2010); semagacestat, a $\gamma$ secretase inhibitor, was tested in two phase 3 trials that had to be prematurely stopped due to serious systemic adverse events (Schor, 2011); several NSAID, including tarenflurbil, show a weak modulating or inhibiting effect on $\gamma$ secretase, but the tested ones were not efficacious in $\mathrm{AD}$. Calcium channel blocker nilvadipine could also reduce the production and augment the clearance of 
$\mathrm{A} \beta$ and is being clinically tested. Investigation of more potent and specific inhibitors of $\gamma$ secretase and efforts to produce $\alpha$ secretase stimulating drugs are being undertaken. In the line of preventing $\mathrm{A} \beta$ aggregation, tramiprosate, which, by binding to $\mathrm{A} \beta$ monomers, prevents formation of oligomers, did not show global clinical benefit in a phase 3 trial, although more studies are needed to clarify its effects in some cognitive areas (Saumier et al., 2009). Other drugs that could interfere in this stage of the $A \beta$ cascade are the zinc and copper chelators, curcumin (also proposed to have $\gamma$ secretase inhibiting properties), epigallocatechin-3-gallate (EGCG) and scyllo-inositol, a compound that promotes dissociation of $\mathrm{A} \beta$ oligomers.

Immunotherapy in $\mathrm{AD}$ is essentially being tried as a way of clearing $A \beta$ deposits through the use of antibodies against this protein. Active immunization in the form of vaccines has produced severe adverse effects (meningoencephalitis), but different techniques, inducing immunization against only a part of the $A \beta$ molecule and not all of it, are being thought of. Passive immunization with monoclonal antibodies is at present under very

\section{REFERENCES}

Albert, M. S., DeKosky, S. T., Dickson, D., Dubois, B., Feldman, H. H., Fox, N. C., Gamst, A., Holtzman, D. M., Jagust, W. J., Petersen, R. C., Snyder, P. J., Carrillo, M. C., Thies, B., and Phelps, C. H. (2011). The diagnosis of mild cognitive impairment due to Alzheimer's disease: recommendations from the National Institute on Aging-Alzheimer's Association workgroups on diagnostic guidelines for Alzheimer's disease. Alzheimers Dement. 7, 270-279.

Alladi, S., Xuereb, J., Bak, T., Nestor, P., Knibb, J., Patterson, K., and Hodges, J. R. (2007). Focal cortical presentations of Alzheimer's disease. Brain 130, 2636-2645.

Alzheimer, A., Stelzmann, R. A., Schnitzlein, H. N., and Murtagh, F. R. (1995). An English translation of Alzheimer's 1907 paper, "Uber eine eigenartige Erkankung der Hirnrinde." Clin. Anat. 8, 429-431.

Amadoro, G., Corset, V., Atlante, A., Florenzano, F., Capsoni, S., Bussani, R., Mercanti, D., and Calissano, P. (2012). Interaction between $\mathrm{NH}(2)$ tau fragment and $\mathrm{A} \beta$ in Alzheimer's disease mitochondria contributes to the synaptic deterioration. Neurobiol. Aging 33, 833.e1-833.e25.

American Psychiatric Association. (2000). Diagnostic and Statistical Manual of Mental Disorders, 4th Edn. Washington, DC: American Psychiatric Association.

Andersen, K., Launer, J., Dewey, E., Letenneur, L., Ott, A., Copeland, M., Dartigues, F., Kragh-Sorensen, P., Baldereschi, M., Brayne, C., Lobo,
A., Martinez-Lage, M., Stijnen, T., Hofman, A., and for the EURODEM Incidence Research Group. (1999). Gender differences in the incidence of $\mathrm{AD}$ and vascular dementia: the EURODEM Studies. Neurology 53, 1992-1997.

Andersen, O. M., Reiche, J., Schmidt, V., Gotthardt, M., Spoelgen, R., Behlke, J., von Arnim, C. A., Breiderhoff, T., Jansen, P., Wu, X., Bales, K. R., Cappai, R., Masters, C. L., Gliemann, J., Mufson, E. J., Hyman, B. T., Paul, S. M., Nykjaer, A., and Willnow, T. E. (2005). Neuronal sorting protein-related receptor sorLA/LR11 regulates processing of the amyloid precursor protein. Proc. Natl. Acad. Sci. U.S.A. 102, 13461-13466.

Antúnez, C., Boada, M., GonzálezPérez, A., Gayán, J., Ramírez-Lorca, R., Marín, J., Hernández, I., MorenoRey, C., Morón, F. J., LópezArrieta, J., Mauleón, A., RosendeRoca, M., Noguera-Perea, F., LegazGarcía, A., Vivancos-Moreau, L., Velasco, J., Carrasco, J. M., Alegret, M., Antequera-Torres, M., Manzanares, S., Romo, A., Blanca, I., Ruiz, S., Espinosa, A., Castaño, S., García, B., Martínez-Herrada, B., Vinyes, G., Lafuente, A., Becker, J. T., Galán, J. J., Serrano-Ríos, M., Alzheimer's Disease Neuroimaging Initiative, Vázquez, E., Tárraga, L., Sáez, M. E., López, O. L., Real, L. M., and Ruiz, A. (2011a). The membranespanning 4-domains, subfamily A (MS4A) gene cluster contains a common variant associated with Alzheimer's disease. Genome Med. 3,33 .

active clinical investigation. The most studied antibodies are bapineuzumab, which is under various phase 3 trials with different doses after a higher dose produced cerebral vasogenic edema in almost 10\% of the patients (Panza et al., 2011), and solanezumab, also in phase 3 trials. Other strategies are being studied, including the use of intravenous immunoglobulins (IVIG).

Lithium and valproate, besides other modes of action, could reduce hyperphosphorylation of tau, but various clinical studies have shown conflicting results. Other compounds judged to act in tau phosphorylation and aggregation (including methylene blue) are under investigation.

Other therapeutic strategies in development include the use of nerve growth factor, etanercept and phosphodiesterase- 5 inhibitors; interventions at the mitochondrial level (for instance with latrepirdine and EGCG); inhibition of the receptor for advanced glycation end products (RAGE); and the use of deep brain stimulation (DBS). The roles of caffeine (or of whole coffee) and of physical activity in the treatment of AD also deserve clarification.

Antúnez, C., Boada, M., López-Arrieta, J., Moreno-Rey, C., Hernández, I., Marín, J., Gayán, J., Alzheimer's Disease Neuroimaging Initiative, González-Pérez, A., Real, L. M. Alegret, M., Tárraga, L., RamírezLorca, R., and Ruiz, A. (2011b). Genetic association of complement receptor 1 polymorphism rs 3818361 in Alzheimer's disease. Alzheimers Dement. 7, e124-e129.

Apostolova, L. G., and Cummings, J. L. (2008). Neuropsychiatric manifestations in mild cognitive impairment: a systematic review of the literature. Dement. Geriatr. Cogn. Disord. 25, 115-126.

Arendt, T. (2009). Synaptic degeneration in Alzheimer's disease. Acta Neuropathol. 118, 167-179.

Arrighi, H. M., Neumann, P. J., Lieberburg, I. M., and Townsend, R. J. (2010). Lethality of Alzheimer disease and its impact on nursing home placement. Alzheimer Dis. Assoc. Disord. 24, 90-95.

Atri, A., Shaughnessy, L. W., Locascio, J. J., and Growdon, J. H. (2008). Longterm course and effectiveness of combination therapy in Alzheimer disease. Alzheimer Dis. Assoc. Disord. 22, 209-221.

Avramopoulos, D. (2009). Genetics of Alzheimer's disease: recent advances. Genome Med. 1, 34.

Ballard, C., Day, S., Sharp, S., Wing, G., and Sorensen, S. (2008). Neuropsychiatric symptoms in dementia: importance and treatment considerations. Int. Rev. Psychiatry 20, 396-404.

Ballard, C., Gauthier, S., Corbett, A., Brayne, C., Aarsland, D., and Jones,
E. (2011a). Alzheimer's disease. Lancet 377, 1019-1031.

Ballard, C., Khan, Z., Clack, H., and Corbett, A. (2011b). Nonpharmacological treatment of Alzheimer disease. Can. J. Psychiatry 56, 589-595.

Bao, F., Wicklund, L., Lacor, P. N., Klein, W. L., Nordberg, A., and Marutle, A. (2012). Different $\beta$ amyloid oligomer assemblies in Alzheimer brains correlate with age of disease onset and impaired cholinergic activity. Neurobiol. Aging 33, 825.e1-825.e13

Barber, R., Ballard, C., McKeith, I. G., Gholkar, A., and O'Brien, J. T. (2000). MRI volumetric study of dementia with Lewy bodies: a comparison with $\mathrm{AD}$ and vascular dementia. Neurology 54, 1304-1309.

Barkhof, F., Polvikoski, T. M., van Straaten, E. C. W., Kalaria, R. N., Sulkava, R., Aronen, H. J., Niinistö, L., Rastas, S., Oinas, M., Scheltens, P., and Erkinjuntti, T. (2007). The significance of medial temporal lobe atrophy: a post-mortem MRI study in the very old. Neurology 69, 1521-1527.

Barnes, L. L., Wilson, R. S., Bienias, J. L., Schneider, J. A., Evans, D. A., and Bennett, D. A. (2005). Sex differences in the clinical manifestations of Alzheimer disease pathology. Arch. Gen. Psychiatry 62, 685-691.

Benson, D. F., Davis, R. J., and Snyder, D. B. (1988). Posterior cortical atrophy. Arch. Neurol. 45, 789-793.

Bertram, L., and Tanzi, R. E. (2005). The genetic epidemiology of neurodegenerative disease. J. Clin. Invest. 115, 1449-1457. 
Biessels, G., Staekenborg, S., Brunner, E., Brayne, C., and Scheltens, P. (2006). Risk of dementia in diabetes mellitus: a systematic review. Lancet $\mathrm{Neu}$ rol. 5, 64-74.

Birks, J., Grimley Evans, J., Iakovidou, V., Tsolaki, M., and Holt, F. E. (2009). Rivastigmine for Alzheimer's disease. Cochrane Database Syst. Rev. 2, CD001191.

Birks, J., and Harvey, R. J. (2006). Donepezil for dementia due to Alzheimer's disease. Cochrane Database Syst. Rev. 1, CD001190.

Blessed, G., Tomlinson, B. E., and Roth, M. (1968). The association between quantitative measures of dementia and of senile change in the cerebral grey matter of elderly subjects. $\mathrm{Br}$. J. Psychiatry 114, 797-811.

Bohnen, N. I., Djang, D. S., Herholz, K., Anzai, Y., and Minoshima, S. (2012). Effectiveness and safety of 18F-FDG PET in the evaluation of dementia: a review of the recent literature. $J$. Nucl. Med. 53, 59-71.

Bots, L., van Kooten, F., Haverkate, F., Meijer, P., Koudstaal, J., Grobbee, D., and Kluft, C. (1998). Coagulation and fibrinolysis markers and risk of dementia: the Dutch vascular factors in dementia study. Haemostasis 28, 216-222.

Braak, H., and Braak, E. (1995). Staging of Alzheimer's disease-related neurofibrillary changes. Neurobiol. Aging 16, 271-278.

Braak, H., and Del Tredici, K. (2011). Alzheimer's pathogenesis: is there neuron to-neuron propagation? Acta Neuropathol. 121, 589-595.

Brookmeyer, R., Corrada, M. M., Curriero, F. C., and Kawas, C. (2002). Survival following a diagnosis of Alzheimer disease. Arch. Neurol. 59, 1764-1767.

Bruandet, A., Richard, F., Bombois, S., Maurage, C. A., Masse, I., Amouyel, P., and Pasquier, F. (2008). Cognitive decline and survival in Alzheimer's disease according to education level. Dement. Geriatr. Cogn. Disord. 25, 74-80.

Burton, E. J., Barber, R., MukaetovaLadinska, E. B., Robson, J., Perry, R. H., Jaros, E., Kalaria, R. N., and O'Brien, J. T. (2009). Medial temporal lobe atrophy on MRI differentiates Alzheimer's disease from dementia with Lewy bodies and vascular cognitive impairment: a prospective study with pathological verification of diagnosis. Brain 132(Pt 1), 195-203.

Cai, Z., Zhao, B., and Ratka, A. (2011). Oxidative stress and $\beta$-amyloid protein in Alzheimer's disease. Neuromolecular Med. 13, 223-250.
Callahan, L. M., Vaules, W. A., and Coleman, P. D. (1999). Quantitative decrease in synaptophysin message expression and increase in cathepsin D message expression in Alzheimer disease neurons containing neurofibrillary tangles. J. Neuropathol. Exp. Neurol. 58, 275-287.

Callahan, L. M., Vaules, W. A., and Coleman, P. D. (2002). Progressive reduction of synaptophysin message in single neurons in Alzheimer disease. J. Neuropathol. Exp. Neurol. 61, 384-395.

Campion, D., Dumanchin, C., Hannequin, D., Dubois, B., Belliard, S., Puel, M., Thomas-Anterion, C., Michon, A., Martin, C., Charbonnier, F., Raux, G., Camuzat, A., Penet, C., Mesnage, V., Martinez, M., Clerget-Darpoux, F., Brice, A., and Frebourg, T. (1999). Early-onset autosomal dominant Alzheimer disease: prevalence, genetic heterogeneity, and mutation spectrum. Am. J. Hum. Genet. 65, 664-670.

Carlesimo, G. A., Perri, R., and Caltagirone, C. (2011). Category cued recall following controlled encoding as a neuropsychological tool in the diagnosis of Alzheimer's disease: a review of the evidence. Neuropsychol. Rev. 21, 54-65.

Carrasquillo, M. M., Belbin, O., Hunter, T. A., Ma, L., Bisceglio, G. D., Zou, F., Crook, J. E., Pankratz, V. S., Dickson, D. W., Graff-Radford, N. R., Petersen, R. C., Morgan, K., and Younkin, S. G. (2010). Replication of CLU, CR1, and PICALM associations with Alzheimer disease. Arch. Neurol. 67, 961-964.

Carrasquillo, M. M., Belbin, O., Hunter, T. A., Ma, L., Bisceglio, G. D., Zou, F., Crook, J. E., Pankratz, V. S., Sando, S. B., Aasly, J. O., Barcikowska, M., Wszolek, Z. K., Dickson, D. W., Graff-Radford, N. R., Petersen, R. C., Morgan, K., and Younkin, S. G. (2011a). Replication of BIN1 association with Alzheimer's disease and evaluation of genetic interactions. J. Alzheimers Dis. 24, 751-758.

Carrasquillo, M. M., Belbin, O., Hunter, T. A., Ma, L., Bisceglio, G. D., Zou, F., Crook, J. E., Pankratz, V. S., Sando, S. B., Aasly, J. O., Barcikowska, M., Wszolek, Z. K., Dickson, D. W., Graff-Radford, N. R., Petersen, R. C., Passmore, P., Morgan, K., and for the Alzheimer's Research UK (ARUK) consortium, and Younkin, S. G. (2011b). Replication of EPHA1 and CD33 associations with lateonset Alzheimer's disease: a multicentre case-control study. $\mathrm{Mol}$. Neurodegener. 6,54 .
Cataldo, J., Prochaska, J., and Glantz, S. (2010). Cigarette smoking is a risk factor for Alzheimer's disease: an analysis controlling for tobacco industry affiliation. J. Alzheimer Dis. 19, 465-480.

Coleman, P., and Yao, P. (2003). Synaptic slaughter in Alzheimer's disease. Neurobiol. Aging 24, 1023-1027.

Coon, K. D., Myers, A. J., Craig, D. W. Webster, J. A., Pearson, J. V., Lince, D. H., Zismann, V. L., Beach, T. G., Leung, D., Bryden, L., Halperin, R. F., Marlowe, L., Kaleem, M., Walker, D. G., Ravid, R., Heward, C. B., Rogers, J., Papassotiropoulos, A., Reiman, E. M., Hardy, J., and Stephan, D. A. (2007). A high-density wholegenome association study reveals that APOE is the major susceptibility gene for sporadic late-onset Alzheimer's disease. J. Clin. Psychiatry 68, 613-618.

Corder, E. H., Saunders, A. M. Strittmatter, W. J., Schmechel, D. E., Gaskell, P. C., Small, G. W., Roses, A. D., Haines, J. L., and PericakVance, M. A. (1993). Gene dose of apolipoprotein E type 4 allele and the risk of Alzheimer's disease in late onset families. Science 261, 921-923.

Corneveaux, J. J., Myers, A. J., Allen, A. N., Pruzin, J. J., Ramirez, M., Engel, A., Nalls, M. A., Chen, K., Lee, W., Chewning, K., Villa, S. E., Meechoovet, H. B., Gerber, J. D., Frost, D., Benson, H. L., O'Reilly, S., Chibnik, L. B., Shulman, J. M., Singleton, A. B., Craig, D. W., Van Keuren-Jensen, K. R., Dunckley, T., Bennett, D. A., De Jager, P. L., Heward, C., Hardy, J. Reiman, E. M., and Huentelman, M. J. (2010). Association of CR1, CLU and PICALM with Alzheimer's disease in a cohort of clinically characterized and neuropathologically verified individuals. Hum. Mol. Genet. 19, 3295-3301.

Cruchaga, C., Nowotny, P., Kauwe, J. S. Ridge, P. G., Mayo, K., Bertelsen, S. Hinrichs, A., Fagan, A. M., Holtzman, D. M., Morris, J. C., Goate, A. M., and Alzheimer's Disease Neuroimaging Initiative. (2011). Association and expression analyses with single-nucleotide polymorphisms in TOMM40 in Alzheimer disease. Arch. Neurol. 68, 1013-1019.

de la Torre, J. C. (2004). Is Alzheimer's disease a neurodegenerative or a vascular disorder? Data, dogma, and dialectics. Lancet Neurol. 3, 184-190.

de la Torre, J. C. (2010). Vascular risk factor detection and control may prevent Alzheimer's disease. Ageing Res. Rev. 9, 218-225.

de Souza, L. C., Lamari, F., Belliard, S., Jardel, C., Houillier, C., De
Paz, R., Dubois, B., and Sarazin, M. (2011). Cerebrospinal fluid biomarkers in the differential diagnosis of Alzheimer's disease from other cortical dementias. J. Neurol. Neurosurg. Psychiatr. 82, 240-246.

Devanand, D. P., Mikhno, A., Pelton, G. H., Cuasay, K., Pradhaban, G., Dileep Kumar, J. S., Upton, N., Lai, R., Gunn, R. N., Libri, V., Liu, X., van Heertum, R., Mann, J. J., and Parsey, R. V. (2010). Pittsburgh compound $\mathrm{B}$ (11C-PIB) and fluorodeoxyglucose (18 F-FDG) PET in patients with Alzheimer disease, mild cognitive impairment, and healthy controls. J. Geriatr. Psychiatry Neurol. 23, 185-198.

Di Domenico, F., Coccia, R., Butterfield, D. A., and Perluigi, M. (2011). Circulating biomarkers of protein oxidation for Alzheimer disease: expectations within limits. Biochim. Biophys. Acta 1814, 1785-1795.

Di Fede, G., Catania, M., Morbin, M., Rossi, G., Suardi, S., Mazzoleni, G., Merlin, M., Giovagnoli, A. R., Prioni, S., Erbetta, A., Falcone, C., Gobbi, M., Colombo, L., Bastone, A., Beeg, M., Manzoni, C., Francescucci, B., Spagnoli, A., Cantù, L., Del Favero, E., Levy, E., Salmona, M., and Tagliavini, F. (2009). A recessive mutation in the APP gene with dominantnegative effect on amyloidogenesis. Science 323, 1473-1477.

Dougall, N. J., Bruggink, S., and Ebmeier, K. P. (2004). Systematic review of the diagnostic accuracy of 99mTc-HMPAO-SPECT in dementia. Am. J. Geriatr. Psychiatry 12, 554-570.

Dubois, B., Feldman, H. H., Jacova, C., Cummings, J. L., Dekosky, S. T., Barberger-Gateau, P., Delacourte, A., Frisoni, G., Fox, N. C., Galasko, D., Gauthier, S., Hampel, H., Jicha, G. A., Meguro, K., O’Brien, J., Pasquier, F., Robert, P., Rossor, M., Salloway, S., Sarazin, M., de Souza, L. C., Stern, Y., Visser, P. J., and Scheltens, P. (2010). Revising the definition of Alzheimer's disease: a new lexicon. Lancet Neurol. 9, 1118-1127.

Dubois, B., Feldman, H. H., Jacova, C., Dekosky, S. T., Barberger-Gateau, P., Cummings, J., Delacourte, A., Galasko, D., Gauthier, S., Jicha, G., Meguro, K., O’brien, J., Pasquier, F., Robert, P., Rossor, M., Salloway, S., Stern, Y., Visser, P. J., and Scheltens, P. (2007). Research criteria for the diagnosis of Alzheimer's disease: revising the NINCDSADRDA criteria. Lancet Neurol. 6, 734-746.

Duron, E., and Hanon, O. (2010). Atrial fibrillation and cognitive function. 
Psychol. Neuropsychiatr. Vieil. 8, 209-214.

Engelhart, M., Geerlings, M., Meijer, J., Kiliaan, A., Ruitenberg, A., van Swieten, J., Stijnen, T., Hofman, A., Witteman, J., and Breteler, M. (2004). Inflammatory proteins in plasma and the risk of dementia. The Rotterdam Study. Arch. Neurol. 61, 668-672.

Ewers, M., Buerger, K., Teipel, S. J., Scheltens, P., Schröder, J., Zinkowski, R. P., Bouwman, F. H., Schönknecht, P., Schoonenboom, N. S., Andreasen, N., Wallin, A., DeBernardis, J. F., Kerkman, D. J., Heindl, B., Blennow, K., and Hampel, H. (2007). Multicenter assessment of CSFphosphorylated tau for the prediction of conversion of MCI. Neurology 69, 2205-2212.

Farrer, L. A., Cupples, L. A., Haines, J. L., Hyman, B., Kukull, W. A., Mayeux, R., Myers, R. H., PericakVance, M. A., Risch, N., and van Duijn, C. M. (1997). Effects of age, sex, and ethnicity on the association between apolipoprotein $\mathrm{E}$ genotype and Alzheimer disease. A meta-analysis. APOE and Alzheimer Disease Meta Analysis Consortium. JAMA 278, 1349-1356.

Ferri, C. P., Prince, M., Brayne, C., Brodaty, H., Fratiglioni, L., Ganguli, M., Hall, K., Hasegawa, K., Hendrie, H., Huang, Y., Jorm, A., Mathers, C., Menezes, P. R., Rimmer, E., Scazufca, M., and Alzheimer's Disease International. (2005). Global prevalence of dementia: a Delphi consensus study. Lancet 366, 2112-2117.

Folstein, M. F., Folstein, S. E., and McHugh, P. R. (1975). Mini-mental state: a practical method for grading the cognitive state of patients for the clinicians. J. Psychiatr. Res. 12, 189-198.

Foster, N. L., Heidebrink, J. L., Clark, C. M., Jagust, W. J., Arnold, S. E., Barbas, N. R., DeCarli, C. S., Turner, R. S., Koeppe, R. A., Higdon, R., and Minoshima, S. (2007). FDG-PET improves accuracy in distinguishing frontotemporal dementia and Alzheimer's disease. Brain 130(Pt 10), 2616-2635.

Fratiglioni, L., Launer, L. J., Andersen, K., Breteler, M. M., Copeland, J. R., Dartigues, J. F., Lobo, A., MartinezLage, J., Soininen, H., and Hofman, A. (2000). Incidence of dementia and major subtypes in Europe: a collaborative study of populationbased cohorts. Neurologic Diseases in the Elderly Research Group. Neurology 54(Suppl. 5), S10-S15.

Fratiglioni, L., Paillard-Borg, S., and Winblad, B. (2004). An active and socially integrated lifestyle in late life might protect against dementia. Lancet Neurol. 3, 343-353.

Galton, C. J., Gomez-Anson, B., Antoun, N., Scheltens, P., Patterson, K., Graves, M., Sahakian, B. J., and Hodges, J. R. (2001). Temporal lobe rating scale: application to Alzheimer's disease and frontotemporal dementia. J. Neurol. Neurosurg. Psychiatr. 70, 165-173.

Galton, C. J., Patterson, K., Xuereb, J. H., and Hodges, J. R. (2000). Atypical and typical presentations of Alzheimer's disease: a clinical, neuropsychological, neuroimaging and pathological study of 13 cases. Brain 123, 484-498.

Galvin, J. E., Roe, C. M., Powlishta, K. K., Coats, M. A., Muich, S. J., Grant, E., Miller, J. P., Storandt, M., and Morris, J. C. (2005). The AD8: a brief informant interview to detect dementia. Neurology 65, 559-564.

Gatz, M., Reynolds, C. A., Fratiglioni, L., Johansson, B., Mortimer, J. A., Berg, S., Fiske, A., and Pedersen, N. L. (2006). Role of genes and environments for explaining Alzheimer disease. Arch. Gen. Psychiatry 63, 168-174.

Gauthier, S., Cummings, J., Ballard, C., Brodaty, H., Grossberg, G., Robert, P., and Lyketsos, C. (2010). Management of behavioral problems in Alzheimer's disease. Int. Psychogeriatr. 22, 346-372.

Genin, E., Hannequin, D., Wallon, D., Sleegers, K., Hiltunen, M., Combarros, O., Bullido, M. J., Engelborghs, S., De Deyn, P., Berr, C., Pasquier, F., Dubois, B., Tognoni, G., Fiévet, N., Brouwers, N., Bettens, K., Arosio, B., Coto, E., Del Zompo, M., Mateo, I., Epelbaum, J., Frank-Garcia, A., Helisalmi, S., Porcellini, E., Pilotto, A., Forti, P., Ferri, R., Scarpini, E., Siciliano, G., Solfrizzi, V., Sorbi, S., Spalletta, G., Valdivieso, F., Vepsäläinen, S., Alvarez, V., Bosco, P., Mancuso, M., Panza, F., Nacmias, B., Bossù, P., Hanon, O., Piccardi, P., Annoni, G., Seripa, D., Galimberti, D., Licastro, F., Soininen, H., Dartigues, J. F., Kamboh, M. I., Van Broeckhoven, C., Lambert, J. C., Amouyel, P., and Campion, D. (2011). APOE and Alzheimer disease: a major gene with semi-dominant inheritance. Mol. Psychiatry 16, 903-907.

Glenner, G. G., and Wong, C. W. (1984). Alzheimer's disease: initial report of the purification and characterization of a novel cerebrovascular amyloid protein. Biochem. Biophys. Res. Commun. 120, 885-890.
Goate, A., Chartier-Harlin, M. C., Mullan, M., Brown, J., Crawford, F., Fidani, L., Giuffra, L., Haynes, A., Irving, N., James, L., Mant, R., Newton, P., Rooke, K., Roques, P., Talbot, C., Pericak-Vance, M., Roses, A., Williamson, R., Rossor, M., Owen, M., and Hardy, J. (1991). Segregation of a missense mutation in the amyloid precursor protein gene with familial Alzheimer's disease. Nature 349, 704-706.

Gold, M., Alderton, C., Zvartau-Hind, M., Egginton, S., Saunders, A M., Irizarry, M., Craft, S., Landreth, G., Linnamagi, U., and Sawchak, S. (2010). Rosiglitazone monotherapy in mild-to-moderate Alzheimer's disease: results from a randomized, double-blind, placebocontrolled phase III study. Dement. Geriatr. Cogn. Disord. 30, 131-146.

Goldman, J. S., Hahn, S. E., Catania, J. W., LaRusse-Eckert, S., Butson, M. B., Rumbaugh, M., Strecker, M. N., Roberts, J. S., Burke, W. Mayeux, R., Bird, T., and American College of Medical Genetics and the National Society of Genetic Counselors. (2011). Genetic counseling and testing for Alzheimer disease: joint practice guidelines of the American College of Medical Genetics and the National Society of Genetic Counselors. Genet. Med. 13, 597-605.

Gómez-Ramos, P., and Asunción Morán, M. (2007). Ultrastructural localization of intraneuronal Abetapeptide in Alzheimer disease brains. J. Alzheimers Dis. 11, 53-59.

Grober, E., and Buschke, H. (1987). Genuine memory deficits in dementia. Dev. Neuropsychol. 3, 13-36.

Grober, E., Buschke, H., Crystal, H., Bang, S., and Dresner, R. (1988). Screening for dementia by memory testing. Neurology 38, 900-903.

Guo, Z., Cupples, A., Kurz, A., Auerbach, S., Volicer, L., Chui, H., Green, C., Sadovnick, A., and Duara, R. (2000). Head injury and the risk of $\mathrm{AD}$ in the MIRAGE study. Neurology 54, 1316-1323.

Gustafson, D. (2006). Adiposity indices and dementia. Lancet Neurol. 5, 713-720.

Götz, J., Schild, A., Hoerndli, F., and Pennanen, L. (2004). Amyloid-induced neurofibrillary tangle formation in Alzheimer's disease: insight from transgenic mouse and tissue-culture models. Int. J. Dev. Neurosci. 22, 453-465.

Hampel, H., Buerger, K., Zinkowski, R., Teipel, S. J., Goernitz, A., Andreasen, N., Sjoegren, M., DeBernardis, J.,
Kerkman, D., Ishiguro, K., Ohno, H., Vanmechelen, E., Vanderstichele, H., McCulloch, C., Moller, H. J., Davies, P., and Blennow, K. (2004). Measurement of phosphorylated tau epitopes in the differential diagnosis of Alzheimer disease: a comparative cerebrospinal fluid study. Arch. Gen. Psychiatry 61, 95-102.

Hampel, H., Bürger, K., Teipel, S. J., Bokde, A. L., Zetterberg, H., and Blennow, K. (2008). Core candidate neurochemical and imaging biomarkers of Alzheimer's disease. Alzheimers Dement. 4, 38-48.

Hardy, J. (1997). Amyloid, the presenilins and Alzheimer's disease. Trends Neurosci. 20, 154-159.

Harold, D., Abraham, R., Hollingworth, P., Sims, R., Gerrish, A., Hamshere, M. L., Pahwa, J. S., Moskvina, V., Dowzell, K., Williams, A., Jones, N., Thomas, C., Stretton, A., Morgan, A. R., Lovestone, S., Powell, J., Proitsi, P., Lupton, M. K., Brayne, C., Rubinsztein, D. C., Gill, M., Lawlor, B., Lynch, A., Morgan, K., Brown, K. S., Passmore, P. A., Craig, D., McGuinness, B., Todd, S., Holmes, C., Mann, D., Smith, A. D., Love, S., Kehoe, P. G., Hardy, J., Mead, S., Fox, N., Rossor, M., Collinge, J., Maier, W., Jessen, F., Schürmann, B., van den Bussche, H., Heuser, I., Kornhuber, J., Wiltfang, J., Dichgans, M., Frölich, L., Hampel, H., Hüll, M., Rujescu, D., Goate, A. M., Kauwe, J. S., Cruchaga, C., Nowotny, P., Morris, J. C., Mayo, K., Sleegers, K., Bettens, K., Engelborghs, S., De Deyn, P. P., Van Broeckhoven, C., Livingston, G., Bass, N. J., Gurling, H., McQuillin, A., Gwilliam, R., Deloukas, P., Al-Chalabi, A., Shaw, C. E., Tsolaki, M., Singleton, A. B., Guerreiro, R., Mühleisen, T. W., Nöthen, M. M., Moebus, S., Jöckel, K. H., Klopp, N., Wichmann, H. E., Carrasquillo, M. M., Pankratz, V. S., Younkin, S. G., Holmans, P. A., O'Donovan, M., Owen, M. J., and Williams, J. (2009). Genome-Wide Association Study identifies variants at CLU and PICALM associated with Alzheimer's disease. Nat. Genet. 41, 1088-1093.

Hebert, L. E., Scherr, P. A., McCann, J. J., Beckett, L. A., and Evans, D. A. (2001). Is the risk of developing Alzheimer's disease greater for women than for men? Am. J. Epidemiol. 153, 132-136.

Helzner, E. P., Scarmeas, N., Cosentino, S., Tang, M. X., Schupf, N., and Stern, Y. (2008). Survival in Alzheimer disease: a multiethnic, populationbased study of incident cases. Neurology 71, 1489-1495. 
Henry, M. L., and Gorno-Tempini, M. L. (2010). The logopenic variant of primary progressive aphasia. Curr. Opin. Neurol. 23, 633-637.

Herrmann, N., Chau, S. A., Kircanski, I., and Lanctôt, K. L. (2011). Current and emerging drug treatment options for Alzheimer's disease: a systematic review. Drugs 71, 2031-2065.

Herrup, K. (2010). Reimagining Alzheimer's disease - an agebased hypothesis. J. Neurosci. 30, 16755-16762.

Heyman, A., Peterson, B., Fillenbaum, G., and Pieper, C. (1996). The consortium to establish a registry for Alzheimer's disease (CERAD). Part XIV: demographic and clinical predictors of survival in patients with Alzheimer's disease. Neurology 46, 656-660.

Hoffman, J. M., Welsh-Bohmer, K. A., Hanson, M., Crain, B., Hulette, C., Earl, N., and Coleman, R. E. (2000). FDG PET imaging in patients with pathologically verified dementia. $J$. Nucl. Med. 41, 1920-1928.

Hollingworth, P., Harold, D., Jones, L., Owen, M. J., and Williams, J. (2011a). Alzheimer's disease genetics: current knowledge and future challenges. Int. J. Geriatr. Psychiatry 26, 793-802.

Hollingworth, P., Harold, D., Sims, R., Gerrish, A., Lambert, J. C., Carrasquillo, M. M., Abraham, R., Hamshere, M. L., Pahwa, J. S., Moskvina, V., Dowzell, K., Jones, N., Stretton, A., Thomas, C., Richards, A., Ivanov, D., Widdowson, C., Chapman, J., Lovestone, S., Powell, J., Proitsi, P., Lupton, M. K., Brayne, C., Rubinsztein, D. C., Gill, M., Lawlor, B., Lynch, A., Brown, K. S., Passmore, P. A., Craig, D., McGuinness, B., Todd, S., Holmes, C., Mann, D., Smith, A. D., Beaumont, H., Warden, D., Wilcock, G., Love, S., Kehoe, P. G., Hooper, N. M., Vardy, E. R., Hardy, J., Mead, S., Fox, N. C., Rossor, M., Collinge, J., Maier, W., Jessen, F., Rüther, E., Schürmann, B., Heun, R., Kölsch, H., van den Bussche, H., Heuser, I., Kornhuber, J., Wiltfang, J., Dichgans, M., Frölich, L., Hampel, H., Gallacher, J., Hüll, M., Rujescu, D., Giegling, I., Goate, A. M., Kauwe, J. S., Cruchaga, C., Nowotny, P., Morris, J. C., Mayo, K., Sleegers, K., Bettens, K., Engelborghs, S., De Deyn, P. P., Van Broeckhoven, C., Livingston, G., Bass, N. J., Gurling, H., McQuillin, A., Gwilliam, R., Deloukas, P., Al-Chalabi, A., Shaw, C. E., Tsolaki, M., Singleton, A. B., Guerreiro, R., Mühleisen, T. W., Nöthen, M. M., Moebus, S.,
Jöckel, K. H., Klopp, N., Wichmann, H. E., Pankratz, V. S., Sando, S. B., Aasly, J. O., Barcikowska, M., Wszolek, Z. K., Dickson, D. W. Graff-Radford, N. R., Petersen, R. C., Alzheimer's Disease Neuroimaging Initiative, van Duijn, C. M., Breteler, M. M., Ikram, M. A., DeStefano, A. L., Fitzpatrick, A. L., Lopez, O., Launer, L. J., Seshadri, S., CHARGE Consortium, Berr, C., Campion, D., Epelbaum, J., Dartigues, J. F., Tzourio, C., Alpérovitch, A., Lathrop, M., EADI1 consortium, Feulner, T. M., Friedrich, P., Riehle, C., Krawczak, M., Schreiber, S., Mayhaus, M., Nicolhaus, S., Wagenpfeil, S., Steinberg, S., Stefansson, H., Stefansson, K., Snaedal, J., Björnsson, S., Jonsson, P. V., Chouraki, V., Genier-Boley, B., Hiltunen, M., Soininen, H., Combarros, O., Zelenika, D., Delepine, M., Bullido, M. J., Pasquier, F., Mateo, I., Frank-Garcia, A., Porcellini, E., Hanon, O., Coto, E., Alvarez, V., Bosco, P., Siciliano, G., Mancuso, M., Panza, F., Solfrizzi, V., Nacmias, B., Sorbi, S., Bossù, P., Piccardi, P., Arosio, B., Annoni, G., Seripa, D., Pilotto, A., Scarpini, E., Galimberti, D., Brice, A., Hannequin, D., Licastro, F., Jones, L., Holmans, P. A., Jonsson. T., Riemenschneider, M., Morgan, K., Younkin, S. G., Owen, M. J., O'Donovan, M., Amouyel, P., and Williams, J. (2011b). Common variants at ABCA7, MS4A6A/MS4A4E, EPHA1, CD33 and CD2AP are associated with Alzheimer's disease. Nat. Genet. 43, 429-435.

Honer, W. G., Dickson, D. W., Gleeson, J., and Davies, P. (1992). Regional synaptic pathology in Alzheimer's disease. Neurobiol. Aging 13, 375-382.

Hort, J., O’Brien, J. T., Gainotti, G., Pirttila, T., Popescu, B. O., Rektorova, I., Sorbi, S., Scheltens, P., and on Behalf of the EFNS Scientist Panel on Dementia. (2010). EFNS guidelines for the diagnosis and management of Alzheimer's disease. Eur. J. Neurol. 17, 1236-1248.

Hyman, B. T., and Goméz-Isla, T. (1994). Alzheimer's disease is a laminar, regional, and neural system specific disease, not a global brain disease. Neurobiol. Aging 15, 353-354.

Hyman, B. T., Van Hoesen, G. W., Beyreuther, K., and Masters, C. L. (1989). A4 amyloid protein immunoreactivity is present in Alzheimer's disease neurofibrillary tangles. Neurosci. Lett. 101, 352-355. Iadecola, C., and Gorelick, P. (2003). Converging pathogenic mechanisms in vascular and neurodegenerative dementia. Stroke 34, 335-337.
Ijsselstijn, L., Dekker, L. J., Stingl, C., van der Weiden, M. M., Hofman, A. Kros, J. M., Koudstaal, P. J., Sillevis Smitt, P. A., Ikram, M. A., Breteler, M. M., and Luider, T. M. (2011) Serum levels of pregnancy zone protein are elevated in presymptomatic Alzheimer's disease. J. Proteome Res. 10, 4902-4910.

Ingelsson, M. (2004). Early Abeta accumulation and progressive synaptic loss, gliosis, and tangle formation in AD brain. Neurology 62, 925-931.

Isaac, M., Vamvakas, S., Abadie, E., Jonsson, B., Gispen, C., and Pani, L. (2011). Qualification opinion of novel methodologies in the predementia stage of Alzheimer's disease: cerebro-spinal-fluid related biomarkers for drugs affecting amyloid burden - regulatory considerations by European Medicines Agency focusing in improving benefit/risk in regulatory trials. Eur. Neuropsychopharmacol. 21, 781-788.

Ito, K., Corrigan, B., Zhao, Q., French, J., Miller, R., Soares, H., Katz, E., Nicholas, T., Billing, B., Anziano, R., Fullerton, T., and Alzheimer's Disease Neuroimaging Initiative. (2011). Disease progression model for cognitive deterioration from Alzheimer's Disease Neuroimaging Initiative database. Alzheimer Dement. 7, 151-160.

Iverson, D. J., Gronseth, G. S., Reger, M. A., Classen, S., Dubinsky, R. M., Rizzo, M., and Quality Standards Subcomittee of the American Academy of Neurology. (2010). Practice parameter update: evaluation and management of driving risk in dementia: report of the Quality Standards Subcommittee of the American Academy of Neurology. Neurology 74, 1316-1324.

Jagust, W., Reed, B., Mungas, D., Ellis, W., and Decarli, C. (2007). What does fluorodeoxyglucose PET imaging add to a clinical diagnosis of dementia? Neurology 69, 871-877.

Jagust, W., Thisted, R., Devous, M. D. Sr., Van Heertum, R., Mayberg, H., Jobst, K., Smith, A. D., and Borys, N. (2001). SPECT perfusion imaging in the diagnosis of Alzheimer's disease: a clinical-pathologic study. Neurology 56, 950-956.

Janssen, J. C., Beck, J. A., Campbell, T. A., Dickinson, A., Fox, N. C., Harvey, R. J., Houlden, H., Rossor, M. N., and Collinge, J. (2003). Early onset familial Alzheimer's disease: mutation frequency in 31 families. Neurology 60, 235-239.

Johnson, J. K., Head, E., Kim, R., Starr, A., and Cotman, C. W. (1999). Clinical and pathological evidence for a frontal variant of Alzheimers Disease. Arch. Neurol. 56, 1233-1239.

Jucker, M., and Walker, L. C. (2011). Pathogenic protein seeding in Alzheimer disease and other neurodegenerative disorders. Ann. Neurol. 70, 532-540.

Jun, G., Naj, A. C., Beecham, G. W., Wang, L. S., Buros, J., Gallins, P. J., Buxbaum, J. D., Ertekin-Taner, N., Fallin, M. D., Friedland, R., Inzelberg, R., Kramer, P., Rogaeva, E., St George-Hyslop, P., Alzheimer's Disease Genetics Consortium, Cantwell, L. B., Dombroski, B. A., Saykin, A. J., Reiman, E. M., Bennett, D. A., Morris, J. C., Lunetta, K. L., Martin, E. R., Montine, T. J., Goate, A. M., Blacker, D., Tsuang, D. W., Beekly, D., Cupples, L. A., Hakonarson, H., Kukull, W., Foroud, T. M., Haines, J., Mayeux, R., Farrer, L. A., PericakVance, M. A., and Schellenberg, G. D. (2010). Meta-analysis confirms CR1, CLU, and PICALM as alzheimer disease risk loci and reveals interactions with APOE genotypes. Arch. Neurol. 67, 1473-1484.

Kalmijn, S., Launer, J., Lindemans, J., Bots, L., Hofman, A., and Breteler, M. (1999). Total homocysteine and cognitive decline in a community based sample of elderly subjects: the Rotterdam Study. Am. J. Epidemiol. 150, 283-289.

Kamboh, M. I., Minster, R. L., Demirci, F. Y., Ganguli, M., Dekosky, S. T., Lopez, O. L., and Barmada, M. M. (2012). Association of CLU and PICALM variants with Alzheimer's disease. Neurobiol. Aging 33, 518-521.

Kantarci, K., and Jack, C. R. Jr. (2003). Neuroimaging in Alzheimer disease: an evidence-based review. Neuroimaging Clin. N. Am. 13, 197-209.

Karow, D. S., McEvoy, L. K., FennemaNotestine, C., Hagler, D. J. Jr, Jennings, R. G., Brewer, J. B., Hoh, C. K., Dale, A. M., and Alzheimer's Disease Neuroimaging Initiative. (2010). Relative capability of MR imaging and FDG PET to depict changes associated with prodromal and early Alzheimer disease. Radiology 256, 932-942.

Kawas, C., and Corrada, M. (2006). Alzheimer's and dementia in the oldest-old: a century of challenges. Curr. Alzheimer Res. 3, 411-419.

Kester, M. I., van der Vlies, A. E., Blankenstein, M. A., Pijnenburg, Y. A., van Elk, E. J., Scheltens, P., and van der Flier, W. M. (2009). CSF biomarkers predict rate of cognitive decline in Alzheimer disease. Neurology 73, 1353-1358. 
Kivipelto, M., Ngandu, T., Fratiglioni, L., Viitanen, M., Kåreholt, I., Winblad, B., Helkala, E., Tuomilehto, J., Soininen, H., and Nissinen, A. (2005). Obesity and vascular risk factors at midlife and the risk of dementia and Alzheimer disease. Arch. Neurol. 62, 1556-1560.

Knopman, D. (2006). Dementia and cerebrovascular disease. Mayo Clin. Proc. 81, 223-230.

Knopman, D. S., DeKosky, S. T., Cummings, J. L., Chuit, H., Corey-Bloom, J., Relkin, N., Small, G. W., Miller, B., and Stevens, J. C. (2001). Practice parameter: diagnosis of dementia (an evidence-based review). Neurology 56, 1143-1153.

Kukull, W. A., Higdon, R., Bowen, J. D., McCormick, W. C., Teri, L., Schellenberg, G. D., van Belle, G., Jolley, L., and Larson, E. B. (2002). Dementia and Alzheimer disease incidence: a prospective cohort study. Arch. Neurol. 59, 1737-1746.

Kuller, L., and Lopez, O. (2011). Dementia and Alzheimer's disease: a new direction. The 2010 Jay L. Foster Memorial Lecture. Alzheimers Dement. 7, 540-550.

LaFerla, F. M. (2010). Pathways linking Abeta and tau pathologies. Biochem. Soc. Trans. 38, 993-995.

LaFerla, F. M., Green, K. N., and Oddo, S. (2007). Intracellular amyloid-beta in Alzheimer's disease. Nat. Rev. Neurosci. 8, 499-509.

LaFerla, F. M., and Oddo, S. (2005). Alzheimer's disease: abeta, tau and synaptic dysfunction. Trends $\mathrm{Mol}$. Med. 11, 170-176.

Lambert, J. C., and Amouyel, P. (2011). Genetics of Alzheimer's disease: new evidences for an old hypothesis? Curr. Opin. Genet. Dev. 21, 295-301.

Lambert, J. C., Heath, S., Even, G., Campion, D., Sleegers, K., Hiltunen, M., Combarros, O., Zelenika, D., Bullido, M. J., Tavernier, B., Letenneur, L., Bettens, K., Berr, C., Pasquier, F., Fiévet, N., BarbergerGateau, P., Engelborghs, S., De Deyn, P., Mateo, I., Franck, A., Helisalmi, S., Porcellini, E., Hanon, O., European Alzheimer's Disease Initiative Investigators, de Pancorbo, M. M., Lendon, C., Dufouil, C., Jaillard, C., Leveillard, T., Alvarez, V., Bosco, P., Mancuso, M., Panza, F., Nacmias, B., Bossù, P., Piccardi, P., Annoni, G., Seripa, D., Galimberti, D., Hannequin, D., Licastro, F., Soininen, H., Ritchie, K., Blanché, H., Dartigues, J. F., Tzourio, C., Gut, I., Van Broeckhoven, C., Alpérovitch, A., Lathrop, M., and Amouyel, P. (2009). Genome-Wide Association Study identifies variants at CLU and
CR1 associated with Alzheimer's disease. Nat. Genet. 41, 1094-1099.

Lambert, J. C., Zelenika, D., Hiltunen, M., Chouraki, V., Combarros, O., Bullido, M. J., Tognoni, G., Fiévet, N., Boland, A., Arosio, B., Coto, E., Del Zompo, M., Mateo, I., FrankGarcia, A., Helisalmi, S., Porcellini, E., Pilotto, A., Forti, P., Ferri, R., Delepine, M., Scarpini, E., Siciliano, G., Solfrizzi, V., Sorbi, S., Spalletta, G., Ravaglia, G., Valdivieso, F., Alvarez, V., Bosco, P., Mancuso, M., Panza, F., Nacmias, B., Bossù, P., Piccardi, P., Annoni, G., Seripa, D., Galimberti, D., Licastro, F., Lathrop, M., Soininen, H., and Amouyel, P. (2011). Evidence of the association of BIN1 and PICALM with the $\mathrm{AD}$ risk in contrasting European populations. Neurobiol. Aging 32, 756.e11-756.e15.

Lapane, K. L., Gambassi, G., Landi, F., Sgadari, A., Mor, V., and Bernabei, R. (2001). Gender differences in predictors of mortality in nursing home residents with AD. Neurology 56, 650-654.

Larson, E. B., Shadlen, M. F., Wang, L., McCormick, W. C., Bowen, J. D., Teri, L., and Kukull, W. A. (2004). Survival after initial diagnosis of Alzheimer disease. Ann. Intern. Med. 140, 501-509.

Launer, L. (2002). Demonstrating the case that $\mathrm{AD}$ is a vascular disease: epidemiologic evidence. Ageing Res. Rev. 1, 61-77.

Launer, L. J., Andersen, K., Dewey, M. E., Letenneur, L., Ott, A., Amaducci, L. A., Brayne, C., Copeland, J. R. M., Dartigues, J.-F., Kragh-Sorensen, P., Lobo, A., Martinez-Lage, J. M., Stijnen, T., Hofman, A., and for the EURODEM Incidence Research Group and Work Groups. (1999). Rates and risk factors for dementia and Alzheimer's disease: results from EURODEM pooled analyses. Neurology 52, 78-84.

Le Bastard, N., Martin, J. J., Vanmechelen, E., Vanderstichele, H., De Deyn, P. P., and Engelborghs, S. (2010). Added diagnostic value of CSF biomarkers in differential dementia diagnosis. Neurobiol. Aging 31, 1867-1876.

Leung, K. K., Barnes, J., Ridgway, G. R., Bartlett, J. W., Clarkson, M. J., Macdonald, K., Schuff, N., Fox, N. C., Ourselin, S., and Alzheimer's Disease Neuroimaging Initiative. (2010). Automated crosssectional and longitudinal hippocampal volume measurement in mild cognitive impairment and Alzheimer's disease. Neuroimage 51, 1345-1359.
Levy-Lahad, E., Wasco, W., Poorkaj, P., Romano, D. M., Oshima, J., Pettingell, W. H., Yu, C. E., Jondro, P. D. Schmidt, S. D., and Wang, K., Crowley, A. C., Fu, Y.-H., Guenette, S. Y., Galas, D., Nemens, E., Wijsman, E. M., Bird, T. D., Schellenberg, G. D., and Tanzi, R. E. (1995a). Candidate gene for the chromosome 1 familial Alzheimer's disease locus. Science 269, 973-977.

Levy-Lahad, E., Wijsman, E. M., Nemens, E., Anderson, L., Goddard, K. A., Weber, J. L., Bird, T. D. and Schellenberg, G. D. (1995b). A familial Alzheimer's disease locus on chromosome 1. Science 269, 970-973.

Lobo, A., Launer, L. J., Fratiglioni, L., Andersen, K., Di Carlo, A., Breteler, M. M., Copeland, J. R., Dartigues, J. F., Jagger, C., Martinez-Lage, J., Soininen, H., and Hofman, A. (2000). Prevalence of dementia and major subtypes in Europe: a collaborative study of population-based cohorts. Neurologic Diseases in the Elderly Research Group. Neurology 54(Suppl. 5), S4-S9.

Lopez, O. L., Becker, J. T., Wahed, A. S., Saxton, J., Sweet, R. A., Wolk, D. A., Klunk, W., and Dekosky, S. T. (2009). Long-term effects of the concomitant use of memantine with cholinesterase inhibition in Alzheimer disease. J. Neurol. Neurosurg. Psychiatr. 80, 600-607.

Lopez, O. L., Brenner, R. P., Becker, J. T. Ulrich, R. F., Boller, F., and DeKosky, S. T. (1997). EEG spectral abnormalities and psychosis as predictors of cognitive and functional decline in probable Alzheimer's disease. $\mathrm{Neu}$ rology 48, 1521-1525.

Loy, C., and Schneider, L. (2006). Galantamine for Alzheimer's disease and mild cognitive impairment. Cochrane Database Syst. Rev. 1, CD001747.

Luchsinger, A., and Mayeux, R. (2004). Dietary factors and Alzheimer's disease. Lancet Neurol. 3, 579-587.

Lutz, M. W., Crenshaw, D. G., Saunders, A. M., and Roses, A. D. (2010). Genetic variation at a single locus and age of onset for Alzheimer's disease. Alzheimers Dement. 6, 125-131.

Massoud, F., Desmarais, J. E., and Gauthier, S. (2011). Switching cholinesterase inhibitors in older adults with dementia. Int Psychogeriatr. 23, 372-378.

Massoud, F., and Léger, G. C. (2011). Pharmacological treatment of Alzheimer disease. Can. J. Psychiatry 56, 579-588.

Mawuenyega, K. G., Sigurdson, W., Ovod, V., Munsell, L., Kasten, T.,
Morris, J. C., Yarasheski, K. E., and Bateman, R. J. (2010). Decreased clearance of CNS beta-amyloid in Alzheimer's disease. Science 330, 1774.

Mayeux, R., Reitz, C., Brickman, A. M., Haan, M. N., Manly, J. J., Glymour, M. M., Weiss, C. C. Yaffe, K., Middleton, L., Hendrie, H. C., Warren, L. H., Hayden, K. M., Welsh-Bohmer, K. A., Breitner, J. C., and Morris, J. C. (2011). Operationalizing diagnostic criteria for Alzheimer's disease and other age-related cognitive impairmentPart 1. Alzheimers Dement. 7, 15-34.

McKhann, G., Drachman, D., Folstein, M., Katzman, R., Price, D., and Stadlan, E. M. (1984). Clinical diagnosis of Alzheimer's disease: report of the NINCDS-ADRDA Work Group under the auspices of Department of Health and Human Services Task Force on Alzheimer's disease. $\mathrm{Neu}$ rology 34, 939-944.

McKhann, G. M., Knopman, D. S., Chertkow, H., Hyman, B. T., Jack, C. R. Jr., Kawas, C. H., Klunk, W. E., Koroshetz, W. J., Manly, J. J., Mayeux, R., Mohs, R. C., Morris, J. C., Rossor, M. N., Scheltens, P., Carrillo, M. C., Thies, B., Weintraub, S., and Phelps, C. H. (2011). The diagnosis of dementia due to Alzheimer's disease: recommendations from the National Institute on Aging-Alzheimer's Association workgroups on diagnostic guidelines for Alzheimer's disease. Alzheimers Dement. 7, 263-269.

McMonagle, P., Deering, F., Berliner, Y., and Kertesz, A. (2006). The cognitive profile of posterior cortical atrophy. Neurology 66, 331-338.

McShane, R., Areosa Sastre, A., and Minakaran, N. (2006). Memantine for dementia. Cochrane Database Syst. Rev. 2, CD003154.

Mesulam, M., Wicklund, A., Johnson, N., Rogalski, E., Léger, G. C., Rademaker, A., Weintraub, S., and Bigio, E. H. (2008). Alzheimer and frontotemporal pathology in subsets of primary progressive aphasia. Ann. Neurol. 63, 709-719.

Mesulam, M. M. (2001). Primary progressive aphasia. Ann. Neurol. 49, 425-432.

Mesulam, M. M., and Moran, M. A (1987). Cholinesterases within neurofibrillary tangles related to age and Alzheimer's disease. Ann. Neurol. 22, 223-228.

Minoshima, S., Foster, N. L., Sima, A. A., Frey, K. A., Albin, R. L., and Kuhl, D. E. (2001). Alzheimer's disease versus dementia with Lewy bodies: 
cerebral metabolic distinction with autopsy confirmation. Ann. Neurol. 50, 358-365.

Morgan, K. (2011). The three new pathways leading to Alzheimer's disease. Neuropathol. Appl. Neurobiol. 37, 353-357.

Mortimer, J. A., Ebbitt, B., Jun, S. P., and Finch, M. D. (1992). Predictors of cognitive and functional progression in patients with probable Alzheimer's disease. Neurology 42, 1689-1696.

Muller, M., Grobbee, D., Aleman, A., Bots, M., and van der Schouw, Y. (2007). Cardiovascular disease and cognitive performance in middleaged and elderly men. Atherosclerosis 190, 143-149.

Murray, I., Proza, J., Sohrabji, F., and Lawler, J. (2011). Vascular and metabolic dysfunction in Alzheimer's disease: a review. Exp. Biol. Med. 236, 772-782.

Musicco, M., Palmer, K., Salamone, G., Lupo, F., Perri, R., Mosti, S., Spalletta, G., di Iulio, F., Pettenati, C., Cravello, L., and Caltagirone, C. (2009). Predictors of progression of cognitive decline in Alzheimer's disease: the role of vascular and sociodemographic factors. J. Neurol. 256, 1288-1295.

Musicco, M., Salamone, G., Caltagirone, C., Cravello, L., Fadda, L., Lupo, F., Mosti, S., Perri, R., and Palmer, K. (2010). Neuropsychological predictors of rapidly progressing patients with Alzheimer's disease. Dement. Geriatr. Cogn. Disord. 30, 219-228.

Nagy, Z., Jobst, K. A., Esiri, M. M., Morris, J. H., King, E. M., MacDonald, B., Litchfield, S., Barnetson, L., and Smith, A. D. (1996). Hippocampal pathology reflects memory deficit and brain imaging measurements in Alzheimer's disease: clinicopathologic correlations using three sets of pathologic diagnostic criteria. Dementia 7, 76-81.

Naj, A. C., Jun, G., Beecham, G. W., Wang, L. S., Vardarajan, B. N., Buros, J., Gallins, P. J., Buxbaum, J. D., Jarvik, G. P., Crane, P. K., Larson, E. B., Bird, T. D., Boeve, B. F., Graff-Radford, N. R., De Jager, P. L., Evans, D., Schneider, J. A., Carrasquillo, M. M., Ertekin-Taner, N., Younkin, S. G., Cruchaga, C., Kauwe, J. S., Nowotny, P., Kramer, P., Hardy, J., Huentelman, M. J., Myers, A. J., Barmada, M. M., Demirci, F. Y., Baldwin, C. T., Green, R. C., Rogaeva, E., St George-Hyslop, P., Arnold, S. E., Barber, R., Beach, T., Bigio, E. H., Bowen, J. D., Boxer, A., Burke, J. R., Cairns, N.
J., Carlson, C. S., Carney, R. M., Carroll, S. L., Chui, H. C., Clark, D. G., Corneveaux, J., Cotman, C. W., Cummings, J. L., DeCarli, C., DeKosky, S. T., Diaz-Arrastia, R., Dick, M., Dickson, D. W., Ellis, W. G., Faber, K. M., Fallon, K. B., Farlow, M. R., Ferris, S., Frosch, M. P., Galasko, D. R., Ganguli, M., Gearing, M., Geschwind, D. H., Ghetti, B., Gilbert, J. R., Gilman, S., Giordani, B., Glass, J. D., Growdon, J. H., Hamilton, R. L., Harrell, L. E., Head, E., Honig, L. S., Hulette, C. M., Hyman, B. T., Jicha, G. A., Jin, L. W., Johnson, N., Karlawish, J., Karydas, A., Kaye, J. A., Kim, R., Koo, E. H., Kowall, N. W., Lah, J. J., Levey, A. I., Lieberman, A. P., Lopez, O. L., Mack, W. J., Marson, D. C., Martiniuk, F., Mash, D. C., Masliah, E., McCormick, W. C., McCurry, S. M., McDavid, A. N., McKee, A. C., Mesulam, M., Miller, B. L., Miller, C. A., Miller, J. W., Parisi, J. E., Perl, D. P., Peskind, E., Petersen, R. C., Poon, W. W., Quinn, J. F., Rajbhandary, R. A., Raskind, M., Reisberg, B., Ringman, J. M., Roberson, E. D., Rosenberg, R. N., Sano, M., Schneider, L. S., Seeley, W., Shelanski, M. L., Slifer, M. A., Smith, C. D., Sonnen, J. A., Spina, S., Stern, R. A., Tanzi, R. E., Trojanowski, J. Q., Troncoso, J. C., Van Deerlin, V. M., Vinters, H. V., Vonsattel, J. P., Weintraub, S., Welsh-Bohmer, K. A., Williamson, J., Woltjer, R. L., Cantwell, L. B., Dombroski, B. A., Beekly, D., Lunetta, K. L., Martin, E. R., Kamboh, M. I., Saykin, A. J., Reiman, E. M., Bennett, D. A., Morris, J. C., Montine, T. J., Goate, A. M., Blacker, D., Tsuang, D. W., Hakonarson, H., Kukull, W. A., Foroud, T. M., Haines, J. L., Mayeux, R., Pericak-Vance, M. A., Farrer, L. A., and Schellenberg, G. D. (2011). Common variants at MS4A4/MS4A6E, CD2AP, CD33 and EPHA1 are associated with late-onset Alzheimer's disease. Nat. Genet. 43, 436-441.

Nelson, P. T., Head, E., Schmitt, F. A., Davis, P. R., Neltner, J. H., Jicha, G. A., Abner, E. L., Smith, C. D., Van Eldik, L. J., Kryscio, R. J., and Scheff, S. W. (2011). Alzheimer's disease is not "brain aging": neuropathological, genetic, and epidemiological human studies. Acta Neuropathol. 121, 571-587.

Nicoll, J. A., Yamada, M., Frackowiak, J., Mazur-Kolecka, B., and Weller, R. O. (2004). Cerebral amyloid angiopathy plays a direct role in the pathogenesis of
Alzheimer's disease. Pro-CAA position statement. Neurobiol. Aging 24 589-597.

Nussbaum, R. L., and Ellis, C. E. (2003). Alzheimer's disease and Parkinson's disease. N. Engl. J. Med. 348, 1356-1364.

Oksengard, A. R., Cavallin, L., Axelsson, R., Andersson, C., Nägga, K., Winblad, B., Eriksdotter-Jönhagen, M., and Wahlund, L. O. (2010). Lack of accuracy for the proposed "Dubois criteria” in Alzheimer's disease: a validation study from the Swedish brain power initiative. Dement. Geriatr. Cogn. Disord. 30, 374-380.

Pan, X. (2011). Microglial phagocytosis induced by fibrillar $\beta$-amyloid is attenuated by oligomeric $\beta$-amyloid: implications for Alzheimer's disease. Mol. Neurodegener. 6, 45.

Panza, F., Frisardi, V., Imbimbo, B. P., Seripa, D., Paris, F., Santamato, A., D’Onofrio, G., Logroscino, G., Pilotto, A., and Solfrizzi, V. (2011) Anti- $\beta$-amyloid immunotherapy for Alzheimer's disease: focus on bapineuzumab. Curr. Alzheimer Res. 8 , 808-817.

Perl, D. (2010). Neuropathology of Alzheimer's disease. Mt. Sinai J. Med. 77, 32-42.

Perry, G., Friedman, R., Shaw, G. and Chau, C. (1987). Ubiquitin is detected in neurofibrillary tangles and senile plaque neurites of Alzheimer's disease brains. Proc. Natl. Acad. Sci. U.S.A. 84, 3033-3036.

Petersen, R. C., and Negash, S. (2008). Mild cognitive impairment: an overview. CNS Spectr. 13, 45-53.

Porsteinsson, A. P., Grossberg, G. T. Mintzer, J., Olin, J. T., and Memantine MEM-MD-12 Study Group. (2008). Memantine treatment in patients with mild to moderate Alzheimer's disease already receiving a cholinesterase inhibitor: a randomized, double-blind, placebocontrolled trial. Curr. Alzheimer Res. 5, 83-89.

Potter, P. E. (2010). Investigational medications for treatment of patients with Alzheimer disease. J. Am. Osteopath. Assoc. 110(Suppl. 8), S27-S36.

Prvulovic, D., and Hampel, H. (2011). Amyloid $\beta(\mathrm{A} \beta)$ and phospho-tau (p-tau) as diagnostic biomarkers in Alzheimer's disease. Clin. Chem. Lab. Med. 49, 367-374.

Qiu, C., Ronchi, D., and Fratiglioni, L. (2007). The epidemiology of the dementias: an update. Curr. Opin. Psychiatry 20, 380-385.

Qiu, C., Winblad, B., Marengoni, A., Klarin, I., Fastbom, J., and
Fratiglioni, L. (2006). Heart failure and risk of dementia and Alzheimer disease: a populationbased cohort study. Arch. Intern. Med. 166, 1003-1008.

Rabinovici, G. D., Jagust, W. J., Furst, A. J., Ogar, J. M., Racine, C. A. Mormino, E. C., O’Neil, J. P., Lal, R. A., Dronkers, N. F., Miller, B. L., and Gorno-Tempini, M. L. (2008). A $\beta$ amyloid and glucose metabolism in three variants of primary progressive aphasia. Ann. Neurol. 64, 388-401.

Reddy, P. H. (2011). Abnormal tau, mitochondrial dysfunction, impaired axonal transport of mitochondria, and synaptic deprivation in Alzheimer's disease. Brain Res. 1415, 136-148.

Reitz, C., Tokuhiro, S., Clark, L. N., Conrad, C., Vonsattel, J. P., Hazrati, L. N. Palotás, A., Lantigua, R., Medrano, M., Z Jiménez-Velázquez, I., Vardarajan, B., Simkin, I., Haines, J. L., Pericak-Vance, M. A., Farrer, L. A., Lee, J. H., Rogaeva, E., GeorgeHyslop, P. S., and Mayeux, R. (2011). SORCS1 alters amyloid precursor protein processing and variants may increase Alzheimer's disease risk. Ann. Neurol. 69, 47-64.

Renner, J. A., Burns, J. M., Hou, C. E., McKeel, D. W., Storandt, M., and Morris, J. C. (2004). Progressive posterior cortical dysfunction. A clinicopathological series. Neurology 63, 1175-1180.

Rey, A. (1958). L'Examen Clinique en Psychologie. Paris: Presses Universitaires de France.

Rogaev, E. I., Sherrington, R., Rogaeva, E. A., Levesque, G., Ikeda, M., Liang, Y., Chi, H., Lin, C., Holman, K., Tsuda, T., Mar, L., Sorbi, S., Nacmias, B., Piacentini, S., Amaducci, L., Chumakov, I., Cohen, D., Lannfelt, L. Fraser, P. E., Rommens, J. M., and St George-Hyslop, P. H. (1995). Familial Alzheimer's disease in kindreds with missense mutations in a gene on chromosome 1 related to the Alzheimer's disease type 3 gene. Nature 376, 775-778.

Rogaeva, E., Meng, Y., Lee, J. H., Gu, Y., Kawarai, T., Zou, F., Katayama, T., Baldwin, C. T., Cheng, R., Hasegawa, H., Chen, F., Shibata, N., Lunetta, K. L., Pardossi-Piquard, R., Bohm, C., Wakutani, Y., Cupples, L. A., Cuenco, K. T., Green, R. C., Pinessi, L., Rainero, I., Sorbi, S., Bruni, A., Duara, R., Friedland, R. P., Inzelberg, R., Hampe, W., Bujo, H., Song, Y. Q., Andersen, O. M., Willnow, T. E., Graff-Radford, N., Petersen, R. C., Dickson, D., Der, S. D., Fraser, P. E., Schmitt-Ulms, G., Younkin, S., Mayeux, R., Farrer, L. A., and 
St George-Hyslop, P. (2007). The neuronal sortilin-related receptor SORL1 is genetically associated with Alzheimer disease. Nat. Genet. 39, 168-177.

Román, G. C., and Royall, D. R. (2004). A diagnostic dilemma: is "Alzheimer's dementia" Alzheimer's disease, vascular dementia, or both? Lancet Neurol. 3, 141.

Roselli, F., Tartaglione, B., Federico, F., Lepore, V., Defazio, G., and Livrea, P. (2009). Rate of MMSE score change in Alzheimer's disease: influence of education and vascular risk factors. Clin. Neurol. Neurosurg. 111, 327-330.

Roses, A. D. (2010). An inherited variable poly- $\mathrm{T}$ repeat genotype in TOMM40 in Alzheimer disease. Arch. Neurol. 67, 536-541.

Roses, A. D., Lutz, M. W., AmrineMadsen, H., Saunders, A. M., Crenshaw, D. G., Sundseth, S. S., Huentelman, M. J., Welsh-Bohmer, K. A., and Reiman, E. M. (2010). A TOMM40 variable-length polymorphism predicts the age of lateonset Alzheimer's disease. Pharmacogenomics J. 10, 375-384.

Rovio, S., Kåreholt, I., Helkala, E., Viitanen, M., Winblad, B., Tuomilehto, J., Soininen, H., Nissinen, A., and Kivipelto, M. (2005). Leisure-time physical activity at midlife and the risk of dementia and Alzheimer's disease. Lancet Neurol. 4, 705-711.

Ruitenberg, A., Heijer, T., Bakker, S., van Swieten, J., Koudstaal, P., Hofman, A., and Breteler, M. (2005). Cerebral hypoperfusion and clinical onset of dementia: the Rotterdam Study. Ann. Neurol. 57, 789-794.

Ruitenberg, A., Ott, A., Swieten, J., Hofman, A., and Breteler, M. (2001). Incidence of dementia: does gender make a difference? Neurobiol. Aging 22, 575-580.

Salomone, S., Caraci, F., Leggio, G. M., Fedotova, J., and Drago, F. (2012). New pharmacological strategies for treatment of Alzheimer's disease: focus on disease-modifying drugs. Br. J. Clin. Pharmacol. 73, 504-517.

Sarazin, M., Berr, C., De Rotrou, J., Fabrigoule, C., Pasquier, F., Legrain, S., Michel, B., Puel, M., Volteau, M., Touchon, J., Verny, M., and Dubois, B. (2007). Amnestic syndrome of the medial temporal type identifies prodromal $\mathrm{AD}$ : a longitudinal study. Neurology 69, 1859-1867.

Saumier, D., Duong, A., Haine, D., Garceau, D., and Sampalis, J. (2009). Domain-specific cognitive effects of tramiprosate in patients with mild to moderate Alzheimer's disease: ADAS-cog subscale results from the
Alphase Study. J. Nutr. Health Aging 13, 808-812.

Saunders, A. M., Strittmatter, W. J., Schmechel, D., George-Hyslop, P. H., Pericak-Vance, M. A., Joo, S. H., Rosi, B. L., Gusella, J. F., CrapperMacLachlan, D. R., Alberts, M. J., Hulette, C., Crain, B., Goldgaber, D., and Roses, A. D. (1993). Association of apolipoprotein E allele epsilon 4 with late-onset familial and sporadic Alzheimer's disease. Neurology 43, 1467-1472.

Schellenberg, G. D., Bird, T. D., Wijsman, E. M., Orr, H. T., Anderson, L., Nemens, E., White, J. A., Bonnycastle, L., Weber, J. L., Alonso, M. E., Potter, H., Heston, L. L., Martin, G. M. (1992). Genetic linkage evidence for a familial Alzheimer's disease locus on chromosome 14. Science 258, 668-671.

Scheltens, P., Leys, D., Barkhof, F., Huglo, D., Weinstein, H. C., Vermersch, P., Kuiper, M., Steinling, M., Wolters, E. C., and Valk, J. (1992). Atrophy of medial temporal lobes on MRI in "probable" Alzheimer's disease and normal ageing: diagnostic value and neuropsychological correlates. J. Neurol. Neurosurg. Psychiatr. 55, 967-972.

Schoonenboom, N. S., Reesink, F. E., Verwey, N. A., Kester, M. I., Teunissen, C. E., van de Ven, P. M., Pijnenburg, Y. A., Blankenstein, M. A., Rozemuller, A. J., Scheltens, P., and van der Flier, W. M. (2012). Cerebrospinal fluid markers for differential dementia diagnosis in a large memory clinic cohort. Neurology 78, 47-54.

Schor, N. F. (2011). What the halted phase III $\gamma$-secretase inhibitor trial may (or may not) be telling us. Ann. Neurol. 69, 237-239.

Seshadri, S., Beiser, A., Au, R., Wolf, P. A., Evans, D. A., Wilson, R. S., Petersen, R. C., Knopman, D. S., Rocca, W. A., Kawas, C. H., Corrada, M. M., Plassman, B. L., Langa, K. M., and Chui, H.C. (2011). Operationalizing diagnostic criteria for Alzheimer's disease and other age-related cognitive impairment-Part 2. Alzheimers Dement. 7, 35-52.

Seshadri, S., Fitzpatrick, A. L., Ikram, M. A., DeStefano, A. L., Gudnason, V., Boada, M., Bis, J. C., Smith, A. V., Carassquillo, M. M., Lambert, J. C., Harold, D., Schrijvers, E. M., Ramirez-Lorca, R., Debette, S., Longstreth, W. T. Jr., Janssens, A. C., Pankratz, V. S., Dartigues, J. F., Hollingworth, P., Aspelund, T., Hernandez, I., Beiser, A., Kuller, L. H., Koudstaal, P. J., Dickson, D. W., Tzourio, C., Abraham, R., Antunez,
C., Du, Y., Rotter, J. I., Aulchenko, Y. S., Harris, T. B., Petersen, R. C., Berr, C., Owen, M. J., LopezArrieta, J., Varadarajan, B. N., Becker, J. T., Rivadeneira, F., Nalls, M. A., Graff-Radford, N. R., Campion, D., Auerbach, S., Rice, K., Hofman, A., Jonsson, P. V., Schmidt, H., Lathrop, M., Mosley, T. H., $\mathrm{Au}$, R., Psaty, B. M., Uitterlinden, A. G., Farrer, L. A., Lumley, T., Ruiz, A., Williams, J., Amouyel, P. Younkin, S. G., Wolf, P. A., Launer, L. J., Lopez, O. L., van Duijn, C. M., Breteler, M. M., CHARGE Consortium, GERAD1 Consortium, and EADI1 Consortium. (2010). Genome-wide analysis of genetic loci associated with Alzheimer disease. JAMA 303, 1832-1840.

Sherrington, R., Froelich, S., Sorbi, S., Campion, D., Chi, H., Rogaeva, E. A., Levesque, G., Rogaev, E. I., Lin, C. Liang, Y., Ikeda, M., Mar, L., Brice, A., Agid, Y., Percy, M. E., ClergetDarpoux, F., Piacentini, S., Marcon, G., Nacmias, B., Amaducci, L., Frebourg, T., Lannfelt, L., Rommens, J. M., and St George-Hyslop, P. H. (1996). Alzheimer's disease associated with mutations in presenilin 2 is rare and variably penetrant. Hum. Mol. Genet. 5, 985-988.

Sherrington, R., Rogaev, E. I., Liang, Y., Rogaeva, E. A., Levesque, G., Ikeda, M., Chi, H., Lin, C., Li, G., Holman, K., Tsuda, T., Mar, L., Foncin, J. F., Bruni, A. C., Montesi, M. P., Sorbi, S., Rainero, I., Pinessi, L., Nee, L., Chumakov, I., Pollen, D., Brookes, A., Sanseau, P., Polinsky, R. J., Wasco, W., Da Silva, H. A., Haines, J. L., Perkicak-Vance, M. A., Tanzi, R. E. Roses, A. D., Fraser, P. E., Rommens, J. M., and St George-Hyslop, P. H. (1995). Cloning of a gene bearing missense mutations in early-onset familial Alzheimer's disease. Nature 375, 754-760.

Sikkes, S. A., de Lange-de Klerk, E. S., Pijnenburg, Y. A., Scheltens, P., and Uitdehaag, B. M. (2009). A systematic review of Instrumental Activities of Daily Living scales in dementia: room for improvement. J. Neurol. Neurosurg. Psychiatr. 80, 7-12.

Silverman, D. H., Small, G. W., Chang, C. Y., Lu, C. S., Kung De Aburto, M. A., Chen, W., Czernin, J., Rapoport, S. I., Pietrini, P., Alexander, G. E., Schapiro, M. B., Jagust, W. J., Hoffman, J. M., Welsh-Bohmer, K. A. Alavi, A., Clark, C. M., Salmon, E., de Leon, M. J., Mielke, R., Cummings, J. L., Kowell, A. P., Gambhir, S. S., Hoh, C. K., and Phelps, M. E. (2001). Positron emission tomography in evaluation of dementia: regional brain metabolism and long-term outcome. JAMA 286, 2120-2127.

Snider, B. J., Fagan, A. M., Roe, C., Shah, A. R., Grant, E. A., Xiong, C., Morris, J. C., and Holtzman, D. M. (2009). Cerebrospinal fluid biomarkers and rate of cognitive decline in very mild dementia of the Alzheimer type. Arch. Neurol. 66, 638-645.

Sperling, R. A., Aisen, P. S., Beckett, L. A., Bennett, D. A., Craft, S., Fagan, A. M., Iwatsubo, T., Jack, C. R. Jr., Kaye, J., Montine, T. J., Park, D. C., Reiman, E. M., Rowe, C. C., Siemers, E., Stern, Y., Yaffe, K., Carrillo, M. C., Thies, B., Morrison-Bogorad, M., Wagster, M. V., and Phelps, C. H. (2011). Toward defining the preclinical stages of Alzheimer's disease: recommendations from the National Institute on Aging-Alzheimer's Association workgroups on diagnostic guidelines for Alzheimer's disease. Alzheimers Dement. 7, 280-292.

Stern, Y. (2006). Cognitive reserve and Alzheimer disease. Alzheimer Dis. Assoc. Disord. 20, S69-S74.

Stern, Y., Albert, M., Brandt, J., Jacobs, D. M., Tang, M. X., Marder, K., Bell, K., Sano, M., Devanand, D. P., Bylsma, F., and Lafleche, G. (1994). Utility of extrapyramidal signs and psychosis as predictors of cognitive and functional decline, nursing home admission, and death in Alzheimer's disease: prospective analyses from the Predictors Study. Neurology 44, 2300-2307.

Strittmatter, W. J., Saunders, A. M., Schmechel, D., Pericak-Vance, M., Enghild, J., Salvesen, G. S., and Roses, A. D. (1993a). Apolipoprotein E: high-avidity binding to betaamyloid and increased frequency of type 4 allele in late-onset familial Alzheimer disease. Proc. Natl. Acad. Sci. U.S.A. 90, 1977-1981.

Strittmatter, W. J., Weisgraber, K. H., Huang, D. Y., Dong, L. M., Salvesen, G. S., Pericak-Vance, M., Schmechel, D., Saunders, A. M., Goldgaber, D., and Roses, A. D. (1993b). Binding of human apolipoprotein $\mathrm{E}$ to synthetic amyloid beta peptide: isoform-specific effects and implications for late-onset Alzheimer disease. Proc. Natl. Acad. Sci. U.S.A. 90, 8098-8102.

Takahashi, R. H., Capetillo-Zarate, E., Lin, M. T., Milner, T. A., and Gouras, G. K. (2010). Co-occurrence of Alzheimer's disease beta-amyloid and tau pathologies at synapses. Neurobiol. Aging 31, 1145-1152.

Tam, C. W. C., Burton, E. J., McKeith, I. G., Burn, D. J., and O'Brien, J. T. (2005). Temporal lobe atrophy on MRI in Parkinson's disease 
with dementia: a comparison with Alzheimer's disease and dementia with Lewy bodies. Neurology 64, 861-865.

Tang-Wai, D. F., Graff-Radford, N. R., Boeve, B. F., Dickson, D. W., Parisi, J. E., Crook, R., Caselli, R. J., Knopman, D. S., and Petersen, R. C. (2004). Clinical, genetic, and neuropathologic characteristics of posterior cortical atrophy. Neurology 63, 1168-1174.

Tariot, P. N., Farlow, M. R., Grossberg, G. T., Graham, S. M., McDonald, S., Gergel, I., and Memantine Study Group. (2004). Memantine treatment in patients with moderate to severe Alzheimer disease already receiving donepezil: a randomized controlled trial. JAMA 291,317-324.

Tedde, A., Nacmias, B., Ciantelli, M., Forleo, P., Cellini, E., Bagnoli, S., Piccini, C., Caffarra, P., Ghidoni, E., Paganini, M., Bracco, L., and Sorbi, S. (2003). Identification of new presenilin gene mutations in early-onset familial Alzheimer disease. Arch. Neurol. 60, 1541-1544.

Terry, R. D. (1963). The fine structure of neurofibrillary tangles in Alzheimer's disease. J. Neuropathol. Exp. Neurol. 22, 629-642.

Terry, R. D., Masliah, E., Salmon, D. P., Butters, N., DeTeresa, R., Hill, R., Hansen, L. A., and Katzman, R. (1991). Physical basis of cognitive alterations in Alzheimer's disease: synapse loss is the major correlate of cognitive impairment. Ann. Neurol. 30, 572-580.

Tschanz, J. T., Corcoran, C. D., Schwartz, S., Treiber, K., Green, R. C., Norton, M. C., Mielke, M. M., Piercy, K., Steinberg, M., Rabins, P. V., Leoutsakos, J. M., Welsh-Bohmer, K. A., Breitner, J. C., and Lyketsos, C.
G. (2011). Progression of cognitive, functional, and neuropsychiatric symptom domains in a population cohort with Alzheimer dementia: the Cache County Dementia Progression study. Am. J. Geriatr. Psychiatry 19, 532-542.

Tyas, L., Manfreda, J., Strain, A., and Montgomery, R. (2001). Risk factors for Alzheimer's disease: a population-based, longitudinal study in Manitoba, Canada. Int. J. Epidemiol. 30, 590-597.

van Duijn, C. M., de Knijff, P., Cruts, M., Wehnert, A., Havekes, L. M., Hofman, A., and Van Broeckhoven, C. (1994). Apolipoprotein E4 allele in a population-based study of early-onset Alzheimer's disease. Nat. Genet. 7, 74-78.

Vemuri, P., Simon, G., Kantarci, K., Whitwell, J. L., Senjem, M. L., Przybelski, S. A., Gunter, J. L., Josephs, K. A., Knopman, D. S., Boeve, B. F., Ferman, T. J., Dickson, D. W., Parisi, J. E., Petersen, R. C., and Jack, C. R. Jr. (2011). Antemortem differential diagnosis of dementia pathology using structural MRI: differentialSTAND. Neuroimage 55, 522-531.

Visser, P. J., Verhey, F., Knol, D. L., Scheltens, P., Wahlund, L. O., FreundLevi, Y., Tsolaki, M., Minthon, L., Wallin, A. K., Hampel, H., Bürger, K., Pirttila, T., Soininen, H., Rikkert, M. O., Verbeek, M. M., Spiru, L., and Blennow, K. (2009). Prevalence and prognostic value of CSF markers of Alzheimer's disease pathology in patients with subjective cognitive impairment or mild cognitive impairment in the DESCRIPA study: a prospective cohort study. Lancet Neurol. 8, 619-627.

Walsh, D. M., and Selkoe, D. J. (2004). Deciphering the molecular basis of memory failure in Alzheimer's disease. Neuron 44, 181-193.

Wang, X., Karp, A., Winblad, B. and Fratiglioni, L. (2002). Latelife engagement in social and leisure activities is associated with a decreased risk of dementia: a longitudinal study from the Kungsholmen project. Am. J. Epidemiol. 155, 1081-1087.

Welge, V., Fiege, O., Lewczuk, P., Mollenhauer, B., Esselmann, H., Klafki, H. W., Wolf, S., Trenkwalder, C., Otto, M., Kornhuber, J., Wiltfang, J., and Bibl, M. (2009). Combined CSF tau, p-tau181 and amyloid-beta 38/40/42 for diagnosing Alzheimer's disease. $J$. Neural Transm. 116, 203-212.

Winblad, B., Grossberg, G., Frölich, L., Farlow, M., Zechner, S., Nagel, J., and Lane, R. (2007). IDEAL: a 6-month, double-blind, placebocontrolled study of the first skin patch for Alzheimer disease. Neurology 69(Suppl. 1), S14-S22.

Wingo, T. S., Lah, J. J., Levey, A. I., and Cutler, D. J. (2012). Autosomal recessive causes likely in early-onset Alzheimer disease. Arch. Neurol. 69, 59-64.

Wirths, O., Multhaup, G., Czech, C., Blanchard, V., Moussaoui, S., Tremp, G., Pradier, L., Beyreuther, K., and Bayer, T. A. (2001). Intraneuronal Abeta accumulation precedes plaque formation in beta-amyloid precursor protein and presenilin-1 doubletransgenic mice. Neurosci. Lett. 306 116-120.

Wyss-Coray, T. (2007). Inflammation in Alzheimer disease: driving force, bystander or beneficial response? Nat. Med. 12, 1005-1015.

Xie, J., Brayne, C., Matthews, F E., and Medical Research Council Cognitive Function and Ageing
Study Collaborators. (2008). Survival times in people with dementia: analysis from population based cohort study with 14 year follow-up. BMJ 336, 258-262.

Xu, G., Liu, X., Yin, Q., Zhu, W., Zhang, R., and Fan, X. (2009). Alcohol consumption and transition of mild cognitive impairment to dementia. Psychiatry Clin. Neurosci. 63, 43-49.

Yao, P. J., Zhu, M., Pyun, E. I., Brooks, A. I., Therianos, S., Meyers, V. E., and Coleman, P. D. (2003). Defects in expression of genes related to synaptic vesicle trafficking in frontal cortex of Alzheimer's disease. Neurobiol. Dis. 12, 97-109.

Conflict of Interest Statement: The authors declare that the research was conducted in the absence of any commercial or financial relationships that could be construed as a potential conflict of interest.

Received: 31 January 2012; paperpending published: 13 February 2012; accepted: 02 April 2012; published online: 20 April 2012.

Citation: Alves L, Correia ASA, Miguel $R$, Alegria $P$ and Bugalho $P$ (2012) Alzheimer's disease: a clinical practiceoriented review. Front. Neur. 3:63. doi: 10.3389/fneur.2012.00063

This article was submitted to Frontiers in Dementia, a specialty of Frontiers in Neurology.

Copyright $($ C 2012 Alves, Correia, Miguel, Alegria and Bugalho. This is an openaccess article distributed under the terms of the Creative Commons Attribution Non Commercial License, which permits non-commercial use, distribution, and reproduction in other forums, provided the original authors and source are credited. 